\title{
Advances in biotechnology of Emblica officinalis Gaertn. syn. Phyllanthus emblica L.: a nutraceuticals-rich fruit tree with multifaceted ethnomedicinal uses
}

\author{
Saikat Gantait ${ }^{1}$ (I) Manisha Mahanta ${ }^{1} \cdot$ Soumen Bera ${ }^{2} \cdot$ Sandeep Kumar Verma ${ }^{3}$
}

Received: 21 October 2020 / Accepted: 24 December 2020 / Published online: 11 January 2021

(c) The Author(s) 2021

\begin{abstract}
Emblica officinalis Gaertn. syn. Phyllanthus emblica L., universally known as 'Amla' or 'Aonla' or 'Indian gooseberry', is a popular fruit tree belonging to the family Euphorbiaceae and order Geraniales. It is said to be the very first tree that originated on earth, as claimed by age-old Indian mythology. Almost all parts of the tree i.e., root, bark, leaf, flower, fruit and seed are utilized in Ayurvedic and Unani medicinal formulations to improve the overall digestive process, decrease fever, act as a blood purifier, relieve asthma and cough, improve heart health, etc. This tree contains major secondary metabolites like emblicanin-A and emblicanin-B, and also is an affluent source of vitamin-C. Additionally, some other secondary metabolites like tannins, gallic acid, pyrogallol, and pectin are also present in significant amounts. Conventional propagation has been improved via suitable interventions of agrotechnology both in production and protection areas. However, the rate of propagation remains slower; therefore, attempts have been made for biotechnological advancements on E. officinalis. The present review makes an attempt to highlight the botanical description, geographical distribution, ethnopharmacological importance, conventional propagation and protection of this medicinal tree, describing the in vitro-based plant organ and tissue culture methods like direct and indirect organogenesis and somatic embryogenesis along with interventions of molecular marker-based biotechnology and nanotechnology. Further, the prospect of the yet-to-be-explored biotechnological methods for secondary metabolite enhancement like cell suspension, protoplast culture, genetic transformation, etc. and their potential for enhanced emblicanin production have also been discussed in this appraisal.
\end{abstract}

Keywords Amla $\cdot$ Callus $\cdot$ Emblicanin $\cdot$ Micropropagation $\cdot$ Molecular markers $\cdot$ Nanoparticles $\cdot$ Somatic embryogenesis

\section{Introduction}

Emblica officinalis Gaertn. (synonym Phyllanthus emblica L.) (Euphorbiaceae family) is a deciduous tree, popular as 'Amla' or 'Aonla' or 'Indian gooseberry'. 'Amla' tree is said to be the very first tree that originated on earth, as claimed by age-old Indian mythology. The fruit of this tree is a

Saikat Gantait

saikatgantait@yahoo.com

1 Crop Research Unit (Genetics and Plant Breeding), Bidhan Chandra Krishi Viswavidyalaya, Mohanpur, Nadia 741252, West Bengal, India

2 College of Agriculture, Bidhan Chandra Krishi Viswavidyalaya, Burdwan 713101, West Bengal, India

3 Institute of Biological Science, SAGE University, Baypass Road, Kailod Kartal, Indore 452020, Madhya Pradesh, India reservoir of various nutraceuticals like calcium, vitamin-C, lysine, minerals, methionine, nicotinic acid, phosphorus, riboflavin, tryptophane and is said to have immune-boosting efficiency against multiple diseases and are also extensively applied in Ayurveda, an Indian ancient system of medicine (Bhagat 2014). Even if the fruit is eaten in its unripe state, it is considered to be beneficial for health. It has also found its application in the food processing, pharmaceutical, and cosmetic sectors. E. officinalis tree is well suited to grow even in saline-sodic and other wasteland soil conditions; and the fruits remain in season for almost ten months. Nowadays, E. officinalis is one of the preferred species for small-scale or marginal-farm-based agro-forest industries in multiple tropical and sub-tropical countries, owing to its high nutraceutical factors and its versatility to be processed into a wide range of pharmaceutical products (Pathak et al. 2003).

The natural propagation frequency of E. officinalis is quite low and the trees are highly prone to several pests and 
pathogens. Quite a few attempts have been made towards the biotechnological improvement of E. officinalis for the past two and half decades, with special emphasis on its mass propagation under in vitro conditions, eventually to yield pathogen-free quality planting materials. However, the reports on the biotechnological improvement of this tree are insufficient to date and a number of strategies are yet to be explored to enrich this highly valued medicinal tree by enhancing the production of its nutraceuticals. In such a backdrop, the present review aims to highlight the significance of applications of $E$. officinalis in pharmaceutical industries and multiple in vitro biotechnological strategies that were adopted for its genetic improvement and mass propagation, for instance, organogenesis (both direct and indirect), somatic embryogenesis, etc. Likewise, the possibilities and prospects of an array of unexplored in vitro biotechnological tools and techniques (such as cell suspension, elicitation, synthetic seed production, hairy root culture, cryopreservation, etc.) have been discussed in a precise way to help the readers in designing their future experiments on the biotechnological improvement of this nutraceuticalrich tree.

\section{Geographical distribution}

E. officinalis, originating from India, is also cultivated in several other tropical and sub-tropical countries (Fig. 1) such as Bangladesh, China (southern part), Malaysia, Mascarene Islands, Myanmar, Pakistan, Sri Lanka, and Uzbekistan (Thilaga et al. 2013). In India, this tree can usually be found in the coastal, tropical, sub-tropical districts and on hill slopes up to a height of $200 \mathrm{~m}$ and up to $4500 \mathrm{ft}$ in the hills. It is also cultivated in the plain land and hilly areas of the valley of Kashmir (Rai et al. 2012; Thilaga et al. 2013). It prevails abundantly in deciduous forests of India (Sai et al. 2002) but lately, accelerated cultivation of this tree was observed in the semi-arid region as well as in the eastern-south-eastern states of India (Nayak et al. 2010).

\section{Botanical features}

An average E. officinalis tree, usually deciduous in nature, is of medium height (8-18 m) (Fig. 2a). The bark is thick $(\sim 12 \mathrm{~mm})$ with light grayish or greenish-brown in color, highlighting a mottled appearance at maturity (Fig. 2b). The leaves of this tree are pinnate in type, simple, alternate, bifarious, sub-sessile, light green in color and arranged in a close pattern along the branchlets (Fig. 2c). Petioles are striated. February-May mark the flowering period (Rai et al. 2012). The flowers appear in greenish-yellow hue along the axillary fascicles with six-parted calyx (Meena et al. 2010). Male flowers are found abundantly in the axils of lower leaflets; whereas, the female flowers (with the three-celled ovary, three-stigmatic, solitary, sessile nature) are fewer in number and usually found in the most exterior floriferous axils along with some male flowers (Treadway 1994). The E. officinalis fruits (measuring $15-20 \mathrm{~mm} \times 18-25 \mathrm{~mm}$ ) are drupe in nature and almost sphere-shaped with a minor conic indentation on both poles (Fig. 2d). The edible smooth fleshy mesocarp is a pale yellow to yellowish-green in appearance and the endocarp that forms the hard stone encasing the seeds turns yellowish-brown during maturity (Khan 2009; Patel and Goyal 2011). Six blurred perpendicular pole-topole lines surrounding six trigonous seeds are observed in two-seeded three-crustaceous cocci (Fig. 2d). Usually, the trees developed from seedlings initiate fruiting around eight years after planting, which is almost three years later than that of the trees developed from budded clones (Kumar et al. 2012a; Rai et al. 2012). The berries generally start to ripen during autumn and each weighs $\sim 60-70 \mathrm{~g}$. The
Fig. 1 Global distribution of Emblica officinalis Gaertn. syn. Phyllanthus emblica L. (Photograph is not in scale) (Source: unpublished photograph of Saikat Gantait)

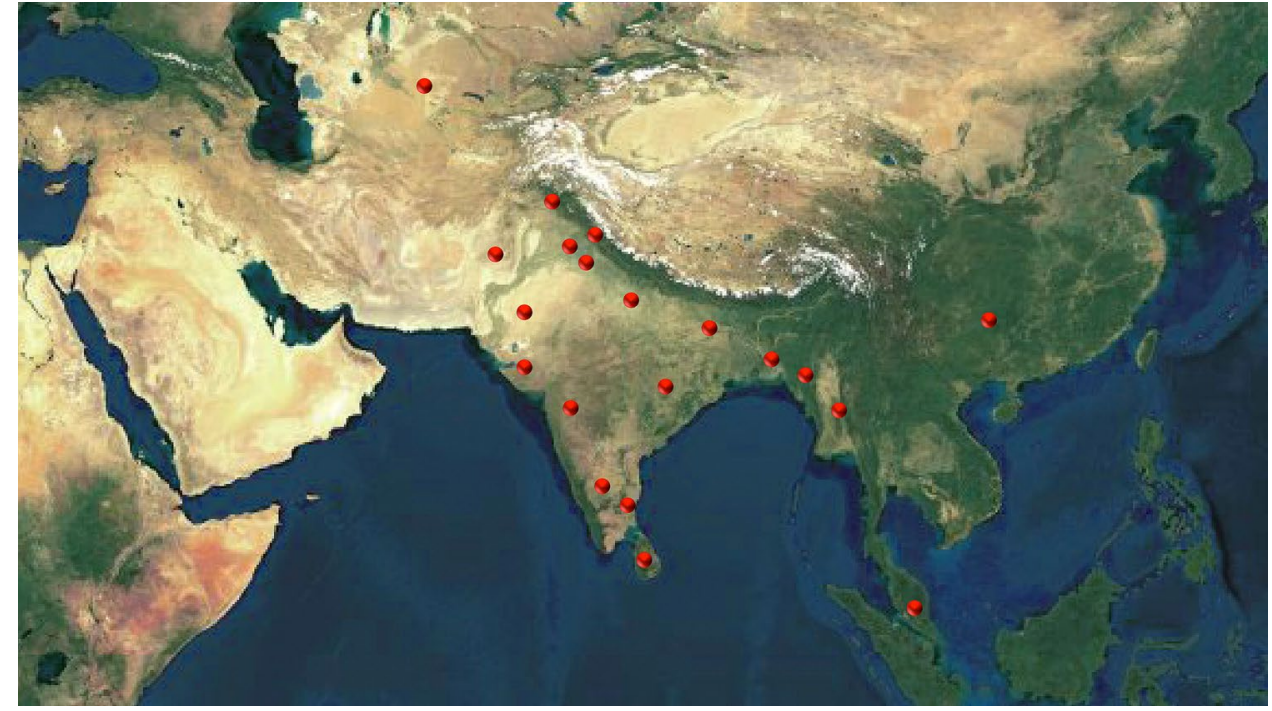


Fig. 2 Salient botanical features of Emblica officinalis Gaertn. syn. Phyllanthus emblica L. a Full-grown trees in deciduous forest, $\mathbf{b}$ fruit-bearing trees with light grayish or greenish-brown barks, $\mathbf{c}$ arrangement of leaves and fruits along the branchlets of the tree, $\mathbf{d}$ almost sphereshaped fruits showing minor conic indentation on both poles and six blurred perpendicular pole-to-pole stripes [Inset: top-edible fleshy yellowishgreen mesocarp; left—endocarp in the form of hard stone encasing the seeds; center-crustaceous cocci, right—smooth, dark brown, and trigonous seeds] (Photographs are not in scale) (Source: unpublished photographs of Saikat Gantait)
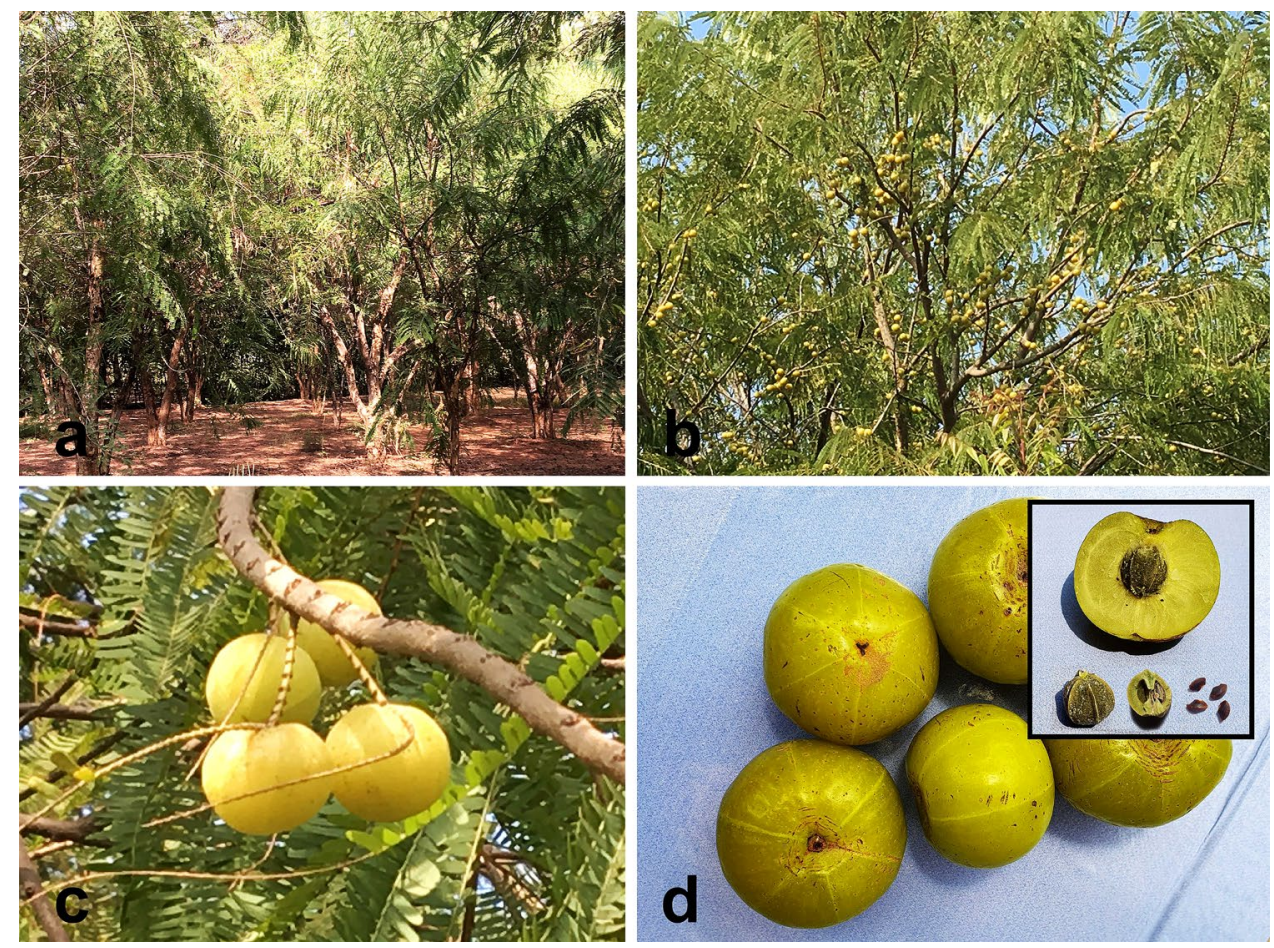

fruit is fibrous and tastes almost astringent, bitter and sour (Kumar et al. 2012b). Seeds are smooth, dark brown and found four-six in number; two seeds enclosed in each cell (Fig. 2d).

\section{Nutraceutical compositions}

Almost all the vegetative and reproductive parts of $E$. officinalis are rich with multiple nutraceuticals (Table 1; Fig. 3), significant of which are iron, calcium, carotene, niacin, phosphorous, riboflavin, thiamine among several others. The seed contains a certain type of fixed oil (yielding $~ 16 \%$ ) (yellowish-brown in color) comprising several fatty acids viz. $44 \%$ linoleic, $28.4 \%$ oleic, $8.8 \%$ linolenic, $3 \%$ palmitic, $2.15 \%$ stearic, $1 \%$ myristic acid; along with multiple essential oils and phosphatides. The bark of this tree is rich in both tannin and leucodelphinidin; the root is enriched with lupeol and ellagic acid, and a significant amount of tannin is found in the leaf and fruit as well (Bhattacharya et al. 1999). A specific amount of D-fructose, D-glucose, D-myoinositol and free sugars are found in an ethanol-soluble fraction derived from this fruit; whereas, an acidic water-soluble fraction of the same comprises pectin with residues of D-arabinosyl, D-galacturonic acid, D-galactosyl, D-glucosyl, D-mannosyl, D-rhamnosyl, and D-xylosyl (Bhattacharya et al. 1999). Emblicanin-A and Emblicanin-B (two low molecular weight hydrolyzable tannins) accompanied by pedunculagin and punigluconin are the integral components found in $E$. officinalis fruits (Kim et al. 2005; Chaudhary et al. 2020); whereas, tannins, gallic acid and pyrogallol are the active principles of this fruit (Veena and Shanthi 2006).

\section{Pharmaceutical uses}

Extracts and various herbal preparations of E. officinalis exhibited their disease-fighting potential against an array of health issues in a comparable way to that of the usual medications. It is because of its multifaceted ethnic, ethnopharmaceutical, and ethnobotanical importance, all the parts of the tree, including the bark, flower, fruit, seed, root, either fresh or dried, are used in the Indian traditional system of Ayurvedic or Unani medicine (Khan 2009; Kumar et al. $2012 b$ ). Concise information on the multifaceted pharmacological properties has been presented (Table 2; Fig. 4).

The fruit may also be utilized in extending longevity while acting as a rejuvenating agent, and conventionally improves the overall digestive process by managing constipation as well. It further decreases fever, acts as a blood purifier, relieves asthma and cough, improves heart health, and has invigorating effects on hair growth. E. officinalis fruits are one of the wealthiest natural reservoirs of vitamin-C that plays a crucial part in counteracting an ample number of ailments (Bhagat 2014). They are beneficial in treating dyslipidemia (Upadya et al. 2019), cancer, chronic periodontitis, dental caries, hyperacidity, hypertension, inflammation, iron deficiency anemia, neurological disorders, obesity, osteoporosis, pulmonary TB, skin diseases, Type 2 diabetes, Type II hyperlipidemia, vitiligo in addition

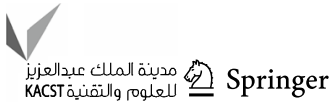


Table 1 Source of different phytochemicals from Emblica officinalis Gaertn. syn. Phyllanthus emblica L

\begin{tabular}{|c|c|c|}
\hline Plant part & Phytochemical & References \\
\hline Bark & $\beta$-sitosterol, Leucodelphinidin, Lupeol, Tannin & Srikumar et al. (2007), Khan (2009) \\
\hline Fruit & $\begin{array}{l}\text { 3-6-di- } O \text {-galloyl-glucose, Alanine, Ascorbic acid, Aspartic acid, } \\
\text { Arginine, } \beta \text {-carotene, Boron, Calcium, Carbohydrates, Chebulagic } \\
\text { acid, Chibulinic acid, Chebulaginic acid, Chebulic acid, Chloride, } \\
\text { Copper, Corilagic acid, Corilagin, Cystine, D-fructose, D-glucose, } \\
\text { Ellagic acid, Emblicanin-A, -B, Emblicol, Ethyl gallate (syn. Phyl- } \\
\text { lemblin), Gallic acid, Gallic acid ethyl ester, Gibberellin } \mathrm{A}_{1} \text {, Gib- } \\
\text { berellin } \mathrm{A}_{3} \text { (syn. Gibberellic acid), Gibberellin } \mathrm{A}_{4} \text {, Gibberellin } \mathrm{A}_{7} \text {, } \\
\text { Gibberellin } \mathrm{A}_{9} \text {, Glucogallin, Glucose, Glutamic acid, Glycine, His- } \\
\text { tidine, Iron, Isoleucine, Leucine, Lysine, L-malic acid 2-O-gallate, } \\
\text { Manganese, Magnesium, Methionine, Myo-inositol, Myristic acid, } \\
\text { Niacin, Nitrogen, Pectin, Phenylalanine, Phosphorus, Phyllem- } \\
\text { blinic acid, Phyllemblic acid, Polysaccharide, Potassium, Proline, } \\
\text { Protein, Quercetin, Riboflavin, Rutin, Selenium, Serine, Silica, } \\
\text { Sodium, Starch, Sucrose, Sulfur, Tannin, Terchebin, Thiamin, } \\
\text { Threonine, Trigalloyl glucose, Tryptophan, Tyrosine Zinc, Zeatin, } \\
\text { Zeatin riboside, Zeatin nucleotide, Phyllantidine, Phyllantine }\end{array}$ & $\begin{array}{l}\text { Ghosal et al. (1996), Jagetia et al. (2004), Srikumar et al. } \\
\text { (2007), Singh et al. (2011), Srinivasan et al. (2018) }\end{array}$ \\
\hline Leaf & $\begin{array}{l}\text { Amlaic acid, Astragalin, Ellagic acid, Gallo-tannin, Kaempferol, } \\
\text { Kaempferol-3-O-glucoside, Phyllantidine, Phyllantine, Rutin, } \\
\text { Tannin }\end{array}$ & Srikumar et al. (2007), Khan (2009) \\
\hline Root & Ellagic acid, Lupeol & \\
\hline Seed & $\begin{array}{l}\beta \text {-sitosterol, Flavonoid, Linoleic acid, Linolenic acid, Myristic acid, } \\
\text { Oleic acid, Palmitic acid, Stearic acid, Tannin }\end{array}$ & Srikumar et al. (2007), Khan (2009), Sriwatcharakul (2020) \\
\hline Shoot & $\begin{array}{l}\text { 3-6-di- } O \text {-galloyl-glucose, } \beta \text {-sitosterol, Chebulagic acid, Chibulinic } \\
\text { acid, Ellagic acid, Gallic acid, Glucogallin, Lupeol }\end{array}$ & Srikumar et al. (2007) \\
\hline Twig & Tannin & \\
\hline Whole plant & Ascorbic acid, Lupenone & \\
\hline
\end{tabular}

to lifestyle diseases, parasitic and other infectious disorders (Variya et al. 2016; Yadav et al. 2017).

It is noteworthy to mention that E. officinalis is a usual component in Ayurvedic preparations (multi-herbal), and especially it is the key constituent in an ancient herbal formulation known as "Chyawanprash", a premier rejuvenating compound that was first cited in the "Charaka Samhita". This formulation is comprised of as many as 43 herbal ingredients along with sugarcane juice, sesame oil, honey, and clarified butter. The other vital and commonly used Ayurvedic herbal mixture is "Triphala (means three fruits) Churna (means dust)" that contains equivalent shares of Terminalia bellirica, T. chebula and P. emblica (devoid of seeds). "Triphala Churna" is taken as a light purgative that purifies the gastro-intestinal tract of the human body (Jagetia et al. 2004).

\section{Conventional propagation}

\section{Climate and soil}

E. officinalis is a hardy sub-tropical fruit-bearing tree and is propagated throughout a wide range of climatic conditions. However, large-scale cultivation of this tree in tropical and dry sub-tropical climate is rather effective (Sengupta et al. 2020). For optimum growth and development of $E$. officinalis tree, 630-800 mm annual rainfall is most favorable, and it can thrive up to $46{ }^{\circ} \mathrm{C}$ since the warm climate is quite advantageous during the onset of its fruit growth (Wali et al. 2015). Being a deciduous and deep-rooted tree species, it has the plasticity to be grown in a broad range of soil type (from sandy loam to clay) and in arid to semiarid regions. The immense potential of E. officinalis has also been proven for commercial-scale cultivation in the salt-affected region, since as large as $\sim 7$ million ha of saline wasteland (Wali et al. 2015) as well as an extent of ravine land (Das et al. 2011) in India is covered by this tree. Growers can gain marked profit via its cultivation even in marginal lands wherein this hardy tree grows well too (Sengupta et al. 2020).

\section{Important cultivars}

In various institutes in India, some promising cultivars of $E$. officinalis have been developed, for instance, 'NA-10', 'NA9', 'NA-8', 'NA-7', 'NA-6', 'Laxmi-52', 'Krishna', 'Kanchan', 'Goma Aishwarya', 'Gujarat-2', 'Gujarat-1', 'Francis', 'Chakaiya', 'BSR-1', and 'Banarasi' (More et al. 2008); and among these cultivars, 'Kanchan' is the highest yielder that produces the best quality fruit (Maholiya et al. 2015). 
Fig. 3 Some of the key phytochemicals found in different parts of Emblica officinalis Gaertn. syn. Phyllanthus emblica L. (Structure source: PubChem https://pubchem.ncbi. nlm.nih.gov) (Source: unpublished photograph of Saikat Gantait)

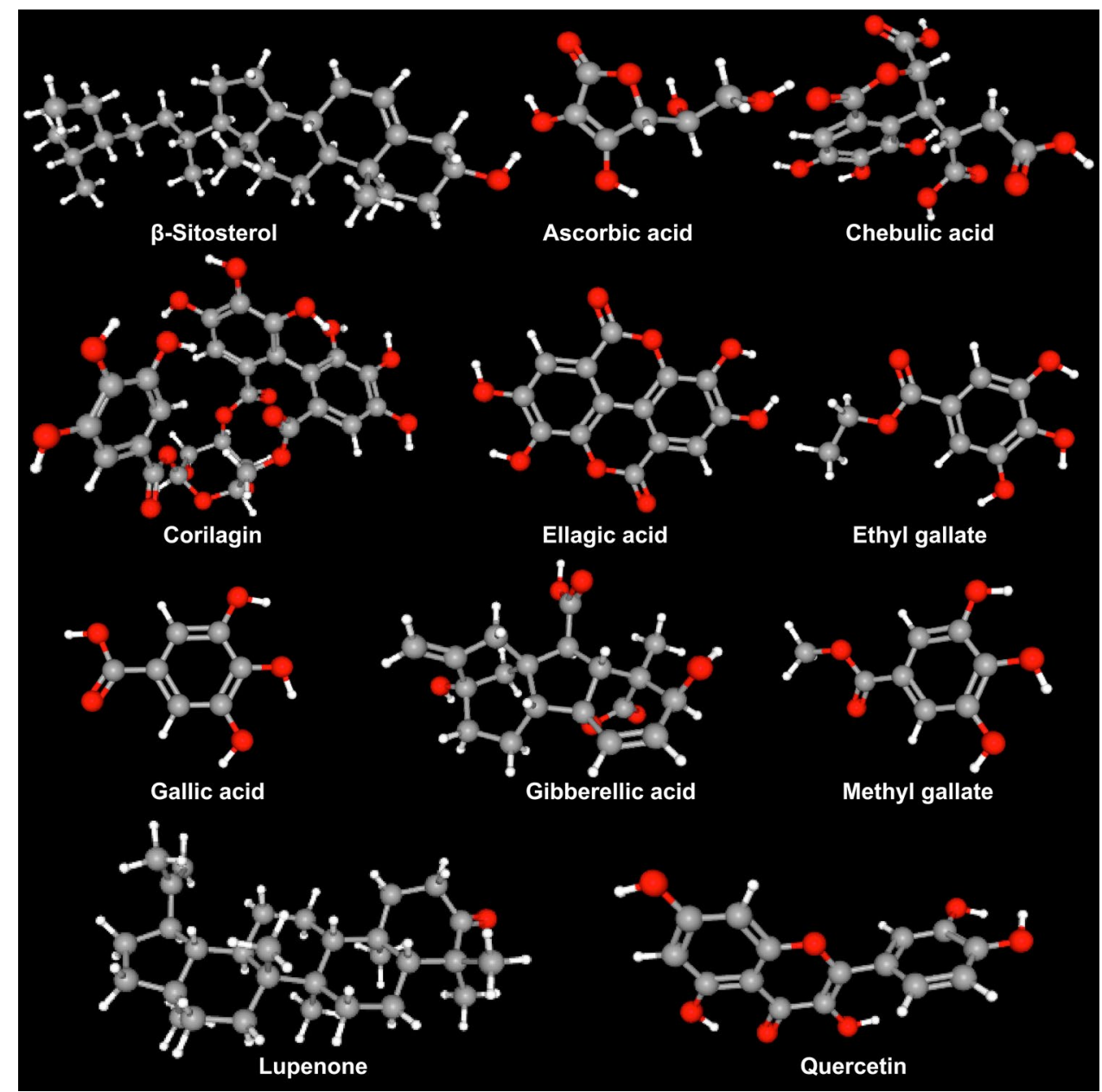

Table 2 Some major pharmacological properties of Emblica officinalis Gaertn. syn. Phyllanthus emblica L

\begin{tabular}{ll}
\hline Property & References \\
\hline Anti-aging & Pal et al. (2017) \\
Anti-cancerous & Mahata et al. (2013), Wiart (2013) \\
Anti-diabetic & Kumar et al. (2012b), Nain et al. (2012), Kalekar et al. (2013), Fatima et al. (2017), Srinivasan et al. \\
& (2018); Sharma et al. (2020) \\
Anti-microbial & Saeed and Tariq (2007), Srikumar et al. (2007), Nath et al. (2012), Dinesh et al. (2017), Singh et al. \\
& (2019a) \\
Anti-mutagenic & Sumitra et al. (2009), Agrawal et al. (2012) \\
Anti-pyretic, analgesic, anti-inflammatory & Mythilypriya et al. (2007), Muthuraman et al. (2011), Gupta et al. (2013), Asmilia et al. (2020) \\
Anti-oxidant & Bafna and Balaraman (2005), Dhanalakshmi et al. (2007); Golechha et al. (2012), Nain et al. (2012), \\
& Rose et al. (2018), Singh et al. (2019b), Majeed et al. (2020) \\
Anti-ulcerous, wound healing & Sai et al. (2002), Bafna and Balaraman (2005), Mehrotra et al. (2011), Chatterjee et al. (2012), Chu- \\
& larojmontri et al. (2013) \\
Cardio-protective & Ojha et al. (2012), Rajak et al. (2004) \\
Chemo-protective & Sharma and Sharma (2011) \\
Hepato-protective & Sultana et al. (2005), Pramyothin et al. (2006), Vasant and Narasimhacharya (2012), Sarkar et al. \\
& (2015), Baliga et al. (2019) \\
Immuno-modulatory & Nemmani et al. (2002), Sai et al. (2002), Srikumar et al. 2005, Patel et al. (2017) \\
Memory enhancing & Vasudevan and Parle (2007), Ali et al. (2013) \\
Neuro-protective & Ashwlayan and Singh (2011), Reddy et al. (2011), Xie et al. (2012), Mathew and Subramanian \\
& (2014), Shalini and Sharma (2015), Justin Thenmozhi et al. (2016)
\end{tabular}


Fig. 4 Diagrammatic presentation of selected pharmacological properties of Emblica officinalis Gaertn. syn. Phyllanthus emblica L. (Source: unpublished photograph of Saikat Gantait)

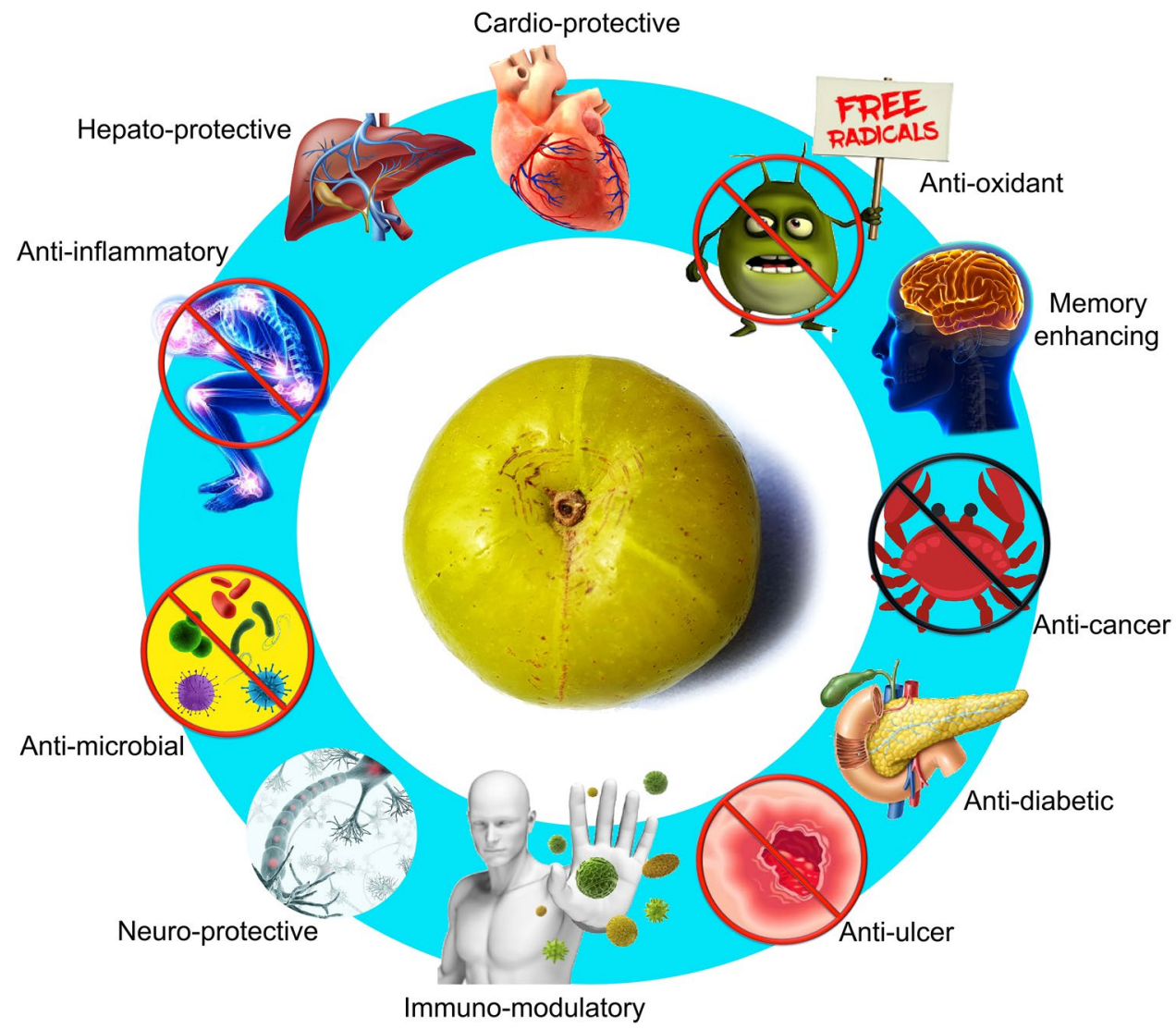

\section{Seed propagation}

E. officinalis trees that are usually raised from seeds produce inferior quality fruit and exhibit long juvenile growth stage. The trees raised by self-sown seeds in forests are not trueto-type and exhibit high variability in terms of irregular pattern of vegetative growth, fruit shape, size, yield (both quality and quantity), etc.; besides, such trees are late-bearing since these need extended time to attain first reproductive stage than that of the vegetatively propagated ones (Sampath Kumar et al. 2012). Moreover, owing to the hard and thick testa, fresh seeds usually do not germinate even if exposed to favorable conditions and consequently, require specific treatments like water-soaking, scarification, stratification, plant growth regulator-treatment, etc. to overcome dormancy (Barathkumar 2019). In regular seed-propagation practice, mature fruits from seed-borne plants are plucked mainly in the months of November-December. Then, the collected fruits are usually sun-dried, so that seeds can be pulled out with gentle pressure. One quintal of indigenous fruits typically yields $1 \mathrm{~kg}$ seeds. Standard test weight (of 1000 seeds) of E. officinalis fresh seeds ranges from 20 to $33 \mathrm{~g}$ (Wali et al. 2015). The conventional time of sowing of E. officinalis seeds is between April and June. The seeds are usually sown in small polybags at the depth of $5 \mathrm{~cm}$ (Singhal et al. 2017). It is evident that immersion of seeds in $\mathrm{GA}_{3}$
$200 \mathrm{ppm}$ solution for $12 \mathrm{~h}$, subsequently 12 -h shade drying significantly improved seed germination, seedling health and vigor. The enzymatic and hormonal mechanism stimulates multiple metabolic activities that result in elongation of shoot and root, as well as increased dry weight of seedlings (Chiranjeevi et al. 2017).

\section{Budding and grafting}

In the case of E. officinalis, budding is the most practical method among all the other modes of vegetative propagation. Amid different budding techniques, patch budding and shield budding are practised for commercial propagation. Generally, one-year-old seedlings having $1 \mathrm{~cm}$ thickness are shield budded with healthy and plump buds, during early July. The success rate of shield budding is quite promising than patch budding (Wali et al. 2015). Apart from budding, particularly for dry areas, softwood grafting is successfully followed with a $70 \%$ success rate. In addition, cleft and veneer grafting are proven to be effective (Wali et al. 2015; Jalal et al. 2019).

\section{Nursery preparation}

Seedbed preparation is a pre-requisite for raising seedlings. Generally, nursery beds are $10-15 \mathrm{~cm}$ elevated using 
farmyard manure (FYM), under partial light. During spring or rainy season, pre-soaked (in water for $48 \mathrm{~h}$ ) seeds are sown at 2-3 cm depth and 2-3 seeds per hill, keeping a spacing of $15 \mathrm{~cm}$ (row-row). Germinated healthy plants become set for ultimate planting are utilized as rootstock for budding as well. For rootstock preparation, 6-12-month-old seedlings are usually considered. Ripen fruits are harvested in the months of November-December. However, following April, the extracted seeds are sown in an elevated nursery bed. For subsequent budding, the seedlings are transplanted in individual beds (Wali et al. 2015)

\section{Orchard establishment and management}

An E. officinalis tree initiates to bear fruits after 3-4 years of planting, and following 10-12 years, attains certain level wherein they are seasoned enough for commercial fruit production even up to 60-70 years (if managed adequately). The layout is followed on bush-free, deeply ploughed and leveled land, supplemented with organic matter and green manure crops (like Sesbania aculeata or Crotalaria juncea). Under sub-tropical climate, planting is mainly started from midAugust and completed within the end of the month itself. Early planting ensures that the plants get a long rainy period, which is necessary for the saplings for their preliminary growth and development. However, the seedlings that are transplanted around mid-July are reported to have the maximum success in budding both during March and July (Banyal and Banyal 2019). Being a deciduous tree, E. officinalis attains the height of $\sim 8-18 \mathrm{~m}$ at maturity. Hence, square planting by maintaining $8-10 \mathrm{~m}$ gap within and between the rows is followed to facilitate sufficient light penetration, smooth cultural operations (like pruning), and adequate fruiting. Hedgerow planting is also being considered nowadays, wherein $8 \mathrm{~m}$ line-to-line and 4-5 m plant-to-plant gap is maintained. E. officinalis is typically propagated directly via seedlings under adverse soil conditions in suitable containers, followed by transplantation of the same at a permanent site, and subsequently in situ budding is carried out. It is necessary for two cultivars to be planted in alternate rows to overcome self-incompatibility. The fields are laid out and marked before planting. Then, pits of $1 \times 1 \times 1 \mathrm{~m}^{3}$ size are excavated at indicated places in the month of April-May and left exposed for at least two weeks (for insect pests eradication). Pits are then loaded with FYM $(\sim 15-20 \mathrm{~kg})$, neem cake $(1 \mathrm{~kg})$, muriate of potash (MoP) (200-300 g), single superphosphate $(500 \mathrm{~g})$ along with Furadan $3 \mathrm{G} \AA$ and Heptachlor ${ }^{\circledR}$, before the rainy season arrives. Thereafter, with the first few showers of rain, the soil is left as such to get leveled and settled appropriately. After planting, to facilitate the proper establishment of plants, instant watering is done prior to the supply of regular irrigation (Wali et al. 2015).
Managing an E. officinalis orchard includes looking after the nutrient and water supply, maintenance of canopy architecture, field cleanliness, and taking plant protection measures on time (Pareek and Kitinoja 2011). Generally, young plants sprout with a specific degree of annual vegetative growth to develop an initial canopy. After two years, the plants build up a suitable canopy to bear fruits. However, for keeping up better growth, flowers and fruits should be removed in the first two years, and periodical watering, hoeing, weeding, plant protection, etc. should be performed accordingly. For young fruit-bearing orchard (2-7 years), trees need extra nutrients to continue desirable growth and fruiting. In fact, young trees exhibit profuse vegetative growth suppressing regular fruiting and, hence, need proper and judicious pruning preferably in the month of March-April, allowing the main branches to reach a height of $0.75-1 \mathrm{~m}$ from the ground. Eventually, only selected 4-6 branches are allowed to grow further (Wali et al. 2015).

\section{Nutrient management}

Application of a combination of organic and inorganic nutrients increases fruit production and quality; whereas, the use of vermicompost significantly improves fruit quality. The physical, biological and chemical properties of soil are influenced by these sources of nutrients. Dosage of manure and fertilizers differs based on soil fertility, age of the plant and frequency of fruiting. Usually, $10 \mathrm{~kg} \mathrm{FYM}, 100 \mathrm{~g}$ nitrogen, $50 \mathrm{~g}$ phosphorus and $100 \mathrm{~g}$ potassium are applied to oneyear-old plant. Annual increment of such dose should be assured up to 10 years, following which a stable dose is applied in the subsequent years. The complete dose of FYM, phosphorus, half of the nitrogen and $\mathrm{MoP}$ are applied around tree basins during December-January. The remaining half is applied in August. In any problematic land, 100-500 g boron, zinc sulfate and copper sulfate are supplemented along with regular fertilizers. Basal application of 100: 50: $50 \mathrm{~g} \mathrm{NPK} /$ plant and 16 tons/ha FYM can also be used as well (Awasthi et al. 2009). Singh and Singh (2015a) suggested that the usage of synthetic auxins ( $\alpha$-naphthalene acetic acid; NAA) and gibberellic acid $\left(\mathrm{GA}_{3}\right)$ in combination with thiourea during mid-May and mid-July may provide an effective solution to minimize yield losses caused by heavy fruit drop. This recommendation can be advocated in sodic soils characterized by production constraints such as limited availability of different mineral nutrients for optimum tree growth and yield. Plant growth regulators (PGRs) and various other nutrients play vital roles in improving the growth, development and quality of E. officinalis fruit. Foliar nutrient sprays are comparatively more effective for rapid absorption and utilization by plants, wherein soil $\mathrm{pH}$ is high and wide range of macro- and micro-elements are unavailable. Two foliar sprays of NAA (30 ppm) in well-established 
orchards during May-July improves fruit quality along with fruit retention (Yadav et al. 2010). As per the experimental findings of Singh et al. (2008), combined spraying of $0.5 \%$ $\mathrm{ZnSO}_{4}+0.4 \% \mathrm{CuSO}_{4}+10$ ppm NAA was found to be effective in improving plant growth and a simultaneous reduction in fruit drop. Foliar feeding of $\mathrm{CuSO}_{4}(0.4 \%)+\mathrm{MnSO}_{4}$ $(0.5 \%)+\mathrm{ZnSO}_{4}(0.4 \%)$ twice during mid-May and midJuly is proven to be the best for improving physico-chemical attributes of E. officinalis fruits (Mishra et al. 2017a); whereas, foliar application of $\mathrm{GA}_{3}(150 \mathrm{ppm})$ was found to be the most effective to increase the vegetative growth and fruit yield (Mishra et al. 2017b). Similarly, foliar spray of boron and zinc showed an improved response in fruit yield. The highest fruit yield and quality (with increased vitamin-C content) per tree were recorded with the foliar sprays of $0.2 \%$ borax $+0.5 \% \mathrm{ZnSO}_{4}(104.80 \mathrm{~kg} /$ tree) (Verma et al. 2008).

\section{Water management}

E. officinalis is being cultivated as a rain-fed tree and no irrigation is required in established orchards in normal soils especially during rainy and winter seasons. Only after manure and fertilizer application (during January-February) in the fruit-bearing plant, first irrigation should be given. However, the application of water should strictly be escaped at the flowering period (mid-March to mid-April). Basin system of irrigation is best suited for E. officinalis. Drip irrigation is also a promising practice and in water scarcity areas, pitcher irrigation is usually recommended for orchard establishment. During a typical dry period, significant stock girth and plant height can be recorded with the applications of a total number of 9 irrigations (based on IW/Pan-E ratio of 0.5 ) along with mulching, which eventually can save up to $20 \mathrm{~cm}$ of irrigation water (four irrigations) on a net area basis. So much so an additional area of orchard may be established with such saved water (Vashisht et al. 2018). Sometimes, fertigation in the place of sole irrigation or fertilizer application records a significant increase in the flowering frequency. Drip fertigation of $125 \%$ recommended dose of fertilizer (RDF) as water-soluble fertilizers (WSF) registered the highest values for the flower parameters (Suresh and Kumar 2014). The highest plant height, trunk girth and plant spread (east-west and north-south) can be registered by application of $125 \%$ RDF in the form of WSF via fertigation (Suresh et al. 2019).

\section{Cropping system}

The tree canopy of $E$. officinalis with sparse foliage facilitates abundant incoming daylight and assists intercropping within available spaces even under full-grown trees (Ghosh and Pal 2010), and thus, during initial 3-4 years of planting, such intercropping offers an exceptional prospect to make use of available interspaces in the orchard. Intercropping with turmeric, ginger and arbi, E. officinalis recorded promising results with respect to yield, available carbon, nitrogen, phosphorus and overall farm economics (Das et al. 2011). Apart from the above-mentioned plant species, Amorphophallus is another shade-preferring plant that can be commercially grown in E. officinalis orchard. Singh and Singh (2015b) demonstrated that growing elephant foot yam as an intercrop in E. officinalis plantation was found most to be suitable based on growth, yield and quality parameters (of both the crop), soil fertility status, gross income, net income, cost-benefit ratio, etc. In case of the arid region, winter crops like chickpea, cumin, fenugreek, and mustard, and rainy-season crop like moth bean are grown as intercrops with E. officinalis (Awasthi et al. 2009). Vegetables like bottle gourd, okra, coriander, cauliflower, pea, and turmeric; flowers like gladiolus and marigold have been found well suited for intercropping. In salt-affected or marginal soils, intercropping of spiny sesbania for few years is beneficial for amending the soil physico-chemical properties. Tuber crops can also be grown befittingly even under the dense shade of orchard (Singh and Singh 2015b). E. officinalis being a deep-rooted, deciduous tree with sparse foliage is proved to be a model plant for 2-, 3- or multi-tier cropping technique. Cropping system models such as E. officinalis with ber or guava (two-tier), or with phalsa (two-tier), or with spiny sesbania and wheat or barley, or with spiny sesbania and onion/ garlic or brinjal, or with spiny sesbania and German chamomile (three-tier), etc. have been found much remunerative.

\section{Fruit maturity, harvesting, and yield}

Time of maturity of E. officinalis fruit is dependent upon desirable yield and processing quality. Commercial traits like days from flowering to maturity, heat units, color of fruit skin and total soluble sugar: acid ratio, etc. are taken into account during ascertaining the maturity index of any E. officinalis cultivar. At the maturity and ripening stage, the fruits initially become light green and then turn greenishyellow or rarely brick red. Maximum ascorbic acid content is recorded in mature fruits, in contrast immature fruits are low in ascorbic acid and mineral content. During November-December, fruits are ready to be harvested via hand picking. Completely developed fruits are plucked (either in early- or in late-hours of a day) without any delay to avoid fruit dropping, particularly for 'Banarasi' and 'Francis' cultivars. A seedling tree takes $6-8$ years to initiate fruit and a budded/grafted tree starts fruit bearing after 3 years of planting, but the latter may keep on fruiting up to 60-75 years of age (Pareek and Kitinoja 2011). An E. officinalis tree may bear 100-300 kg fruits/tree, yielding 15-20 tons/ha (Wali et al. 2015). The better yield of E. officinalis can be attained if better fruit retention along with other yield attributing 
characters is assured. Maholiya et al. (2015) reported the maximum fruit yield in cultivar 'Kanchan' $(99.79 \mathrm{~kg} /$ tree) trailed by 'Krishna' (76.55 kg/tree). However, as high as 220-280 kg per tree fruit yield may generally be recorded if proper agrotechnology is followed (Yadav et al. 2010). The mature fruits are usually very firm and, thus, facilitate large-scale harvesting, carriage and marketing even to distant regions (Pareek and Kitinoja 2011).

\section{Plant protection}

\section{Physiological disorders and their management}

Chilling injury, necrosis, pink spots, and white specks are some major physiological disorders that affect the quality of E. officinalis fruits. Chilling injury results in the splitting of peel and sporadic ripening of fruits that eventually leads to decay. To avoid such injury, storage temperature should be optimized around $12{ }^{\circ} \mathrm{C}$ (Pareek 2010). During the hardening of endocarp, browning of innermost mesocarpic tissues along with epicarp results in the blackened fruit surface in the form of necrosis. In addition, owing to the deficiency of boron, random pink spots appeared on E. officinalis fruits that eventually deteriorate the fruit quality. To control both these disorders, spraying of borax (0.6\%) thrice at two-week intervals (during September-October) is useful (Sharma 2006; Pareek 2010). White specks are the other major disorder that causes poor appearance and spongy texture of fruit at the curing and pickling stage. The frequency of white specks can be minimized via preservation of fruit segments in $0.04 \% \mathrm{~K}_{2} \mathrm{~S}_{2} \mathrm{O}_{5}$ and $10 \% \mathrm{NaCl}$ solution, followed by salting and dehydrating with $0.02 \% \mathrm{~K}_{2} \mathrm{~S}_{2} \mathrm{O}_{5}$ and $10 \% \mathrm{NaCl}$ after four weeks of storage (Premi et al. 1998).

\section{Pathological disorders and their management}

Major pathological diseases found in E. officinalis are rust, anthracnose, fruit rots, blue mold rots, etc. (Pareek and Kitinoja 2011), among which, rust is economically most important. Black pustules followed by ring pattern appearance on fruits are developed. Revenelia emblica Syd is the causal organism, which is an obligate parasite. Clean cultivation along with the removal of infected fruits and leaves (proper pruning) decreased infestation of this disease. Spraying $0.2 \%$ Zineb or $0.5 \%$ sulfur (wettable) three times from the month of July at four-week intervals proved to be effective for rust management. During August-September, Colletotrichum state of Glomerella cingulata results in anthracnose of fruits and leaflets. Dried up leaves initially appear that turn into dark brown smudges with the red margin and yellow halos (Pareek and Kitinoja 2011). Such infected plant parts should be amputated during inception of the disease. In addition, $0.1 \%$ Carbendazim or $0.2 \%$ Difolatan spray is recommended to get rid of anthracnose (Nallathambi et al. 2007; Wali et al. 2015). A pre-harvest fruit (Phoma) rot is usually observed frequently during the colder month of January. Such rot appears as small, lemon-colored lesions, which becomes enlarged and gets covered with funicles of conidiophores bearing spore (Mishra 1988; Wali et al. 2015). The disease usually resulted in a pre-mature fruit drop, which later mummified on the ground (Verma and Singh 2018). The disease can be characterized by necrotic spots, which extend to both ends of the fruit forming an eye-shaped spot. Multiple such lesions merge to create bigger pustules in heavily infested fruits (Nallathambi et al. 2007). Due to Phoma infection (by Phoma exigna), very quick decline in vitamin-C content is recorded in comparison to that of the gradual decline under storage condition (Reddy and Laxminarayana 1984). Other rots that are not so widespread are caused by Aspergillus luchuensis and Fusarium acuminatum (Sumbali and Badyal 1990). Dry rot sets off by Cladosporium tenuissiumum and C. cladosporoids is commonly seen in November and March, respectively. The initially colorless area along with a slightly soft spot appears that further turns into a round dark brown lesion (Jamaluddin 1978). In such circumstances, sodium hypochlorite (100-150 ppm) along with relevant anti-fungal agents should be applied depending on the source and degree of infestation (Pareek and Kitinoja 2011). Alternatively, pre-harvest dip of fruits at the rate of $4 \%$ borax or two sprays of $0.01 \%$ calcium nitrate with $0.1 \%$ Topsin $\mathrm{M}$ is efficient against fruit rot (Nath et al. 1992; Yadav and Singh 1999). Among the other pathological disorders, an infestation of Penicillium islandicum causes blue mold rot exhibiting brown patches with water-soaked areas. Further, three colors, i.e., bright yellow, purple-brown and bluish-green develop in heavy infestation. Yellow liquid exudes drops from the diseased patches; fruits exert bad odor and turn into a bluish-green or beaded look eventually. Nonetheless, proper fruit handling and good sanitary conditions during storage along with $\mathrm{NCl}_{3}$ and ozone gas treatment remains effective. In addition, fruit treatment with borax@0.5 g/l of water is promising as well (Wali et al. 2015).

\section{Insect pests and their management}

There is an array of insect pests from the order of Lepidoptera (Betousa stylophora Swinhae, Celepa celtis, Gracillaria acidula, Indarbela tetraonis and Virachola Isocrates), Homoptera (Oxyrhachis tarandus, Nipaecoccus vastator, and Ceciaphis emblica), Isoptera (Odontotermes spp.), and Cleoptera (Myllocerus discolor) (Pareek and Kitinoja 2011). Juvenile fruits are affected by fruit borers that feed on the developing seeds after laying of eggs and the subsequent emergence of caterpillars. During July-August, Endosulphan $(0.05 \%)$ spray is effective against fruit borers, apart 
from the collection and destruction of affected fruits. As a precautionary measure, near E. officinalis orchards, pomegranate cultivation should be avoided (Pareek and Kitinoja 2011; Wali et al. 2015). The other category of the caterpillar is 'bark-eating' type (Indarbela quadrinotata, I. tetraonis) that causes up to $80 \%$ damage to the whole plant. The main trunk is affected and trunk tunnels are formed by this caterpillar. Feed on the bark under silken ribbon-shaped webs. Reduction of overcrowded branches and clean cultivation can manage this pest, but with an increasing infestation Furadan or Endrin spray (0.03\%) during February-March or September-October is proven to be effective (Wali et al. 2015). Tender shoots are susceptible to shoot-gall maker (Betanosa stylophora). During the rainy season, young caterpillars bore into tender shoots and feed in pits. The damaged region develops gall formation. Shoot-gall maker attacks all the available varieties. The affected parts should be pruned and burnt to minimize the infestation. Iron or spoke can be inserted to kill the larvae or injecting Dichlorovas or Endosulphon@ 0.05\% in the holes can equally be effective apart from the collection and mass destruction of gall affected shoots. Additionally, the application of $0.05 \%$ Monocrotophos in the month of July-August remains quite useful. Finally, aphids (Schoutedenia emblica) are gaining importance rapidly in the cultivation of E. officinalis as it infests tender shoots, leaves, flower bud and fruits. A single spray of $2 \%$ neem seed kernel extract, or $0.03 \%$ Dimethoate or $0.05 \%$ Phosalone at the initiation of new flush is efficient against aphids (Wali et al. 2015).

\section{In vitro propagation}

In vitro propagation ensures the rapid multiplication of plantlets from plant cells and tissues on nutrient media under aseptic conditions (Mukherjee et al. 2019). Conventionally, E. officinalis is propagated through seeds and asexually by budding and grafting. Propagation through seeds is not beneficial since seeds possess dormancy and do not produce trueto-type plants owing to cross-pollination and seed-derived plants bear inferior quality fruits (Mishra et al. 2011). To overcome this issue, micropropagation techniques were employed to produce large-scale true-to-type and diseasefree plants. Several methods of in vitro propagation have been executed in E. officinalis to date. This review compiles different approaches attempted for micropropagation and developmental work done in E. officinalis (Fig. 5).

\section{Selection of explant}

A proper selection of explant is important in any micropropagation study. The stage, regenerating ability and preferably disease-free were taken into consideration while selecting explant (Mukherjee et al. 2019). A number of explants such as nodal segments, shoots, hypocotyls, epicotyls, embryo, root-shoot node, and leaf have been used by researchers for both direct and indirect regeneration in E. officinalis (Table 3). Nodal segment and shoots are generally used for direct organogenesis (Verma and Kant 1999; Mishra and Pathak 2001; Mishra et al. 2006; Goyal and Bhadauria 2008; Patidar et al. 2010). Preferably, the 10-15th nodal segment portion was taken as they gave better response than the young nodal segment because they cannot withstand the disinfection process and older segment showed lower response because of mature tissues (Mishra and Pathak 2001). For indirect organogenesis via callus formation, cotyledons, hypocotyls, epicotyls, embryo, and leaf are being used (Sehgal and Khurana 1985; Gupta et al. 1994; Verma and Kant 1999; Al-Sabah et al. 2012; Priyanka et al. 2014;
Fig. 5 Diagram exhibiting the research areas that have been already studied and the areas that are yet to be explored regarding in vitro cell, tissue and organ culture of Emblica officinalis Gaertn. syn. Phyllanthus emblica L. (Source: unpublished photograph of Saikat Gantait)

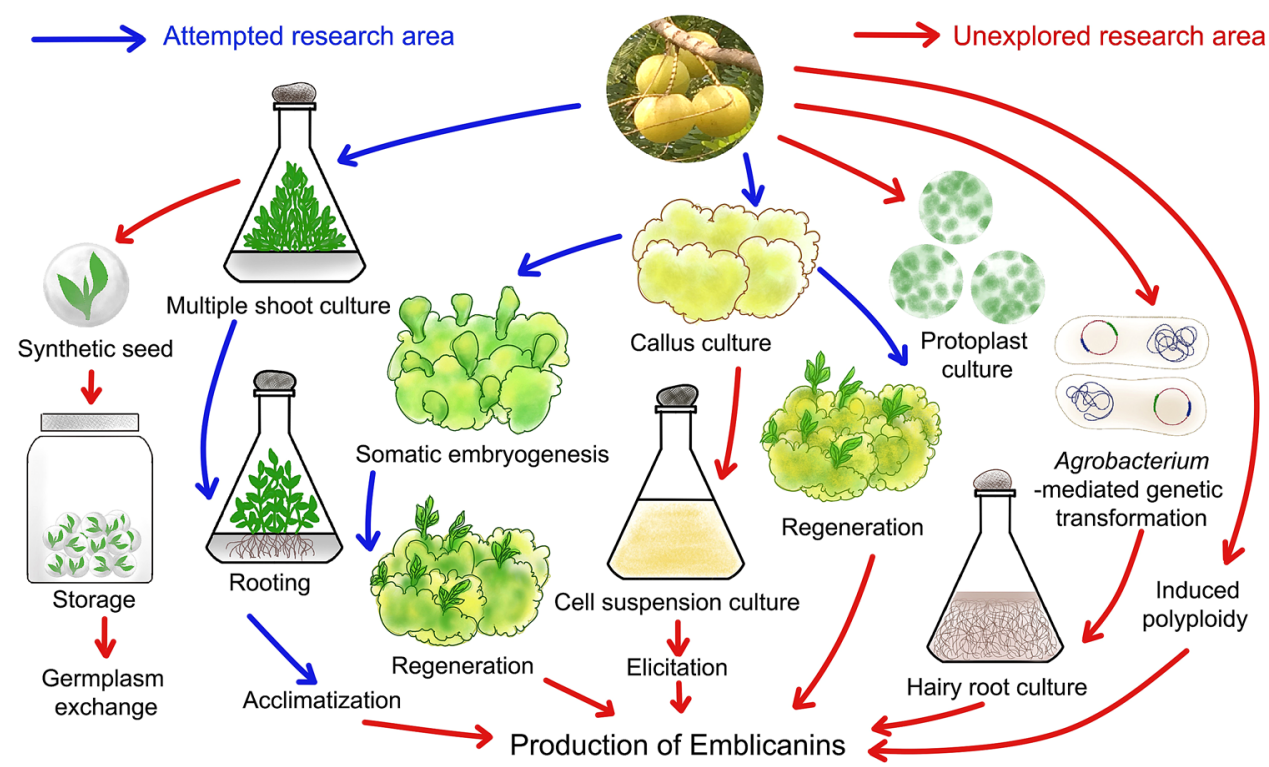




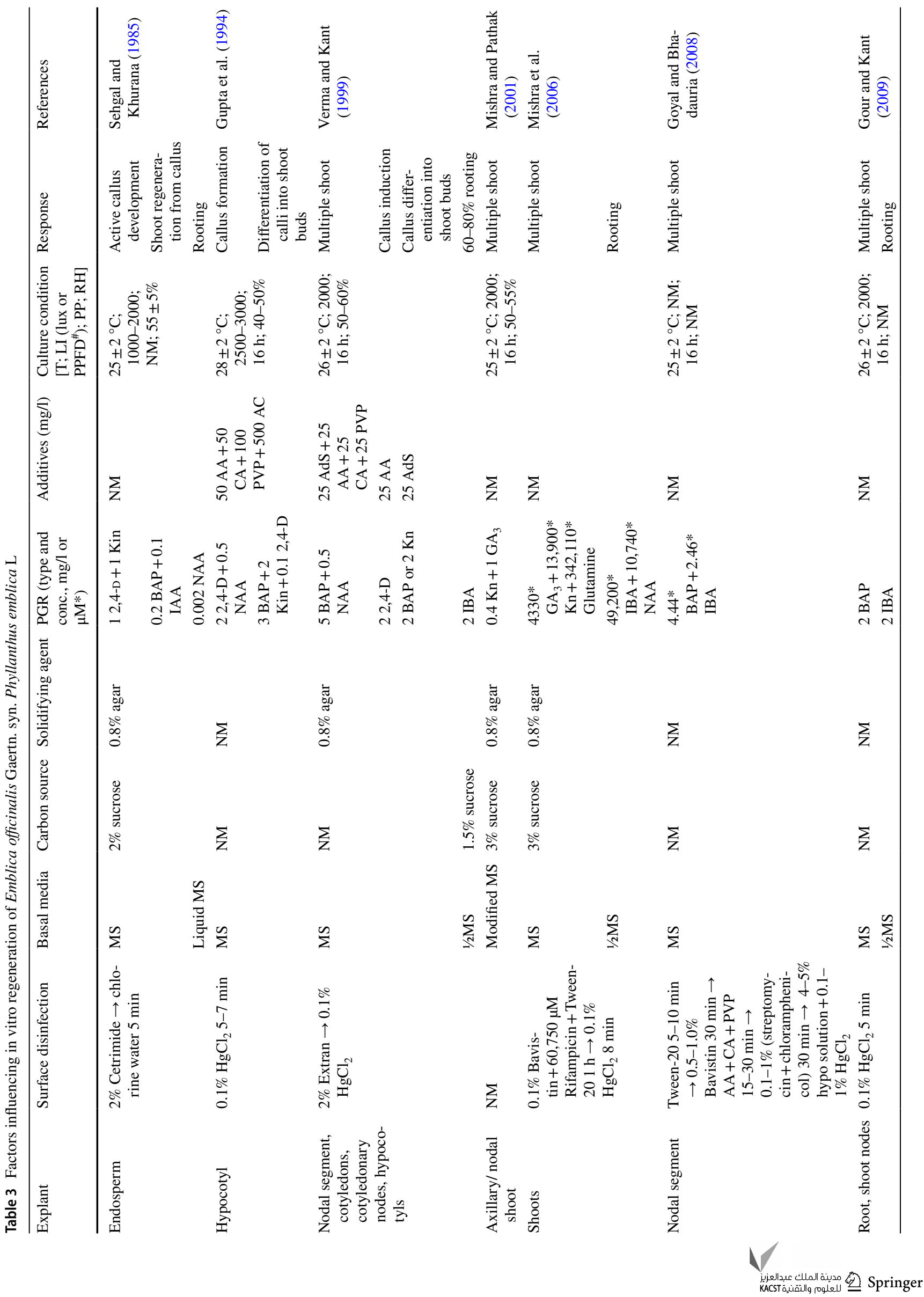




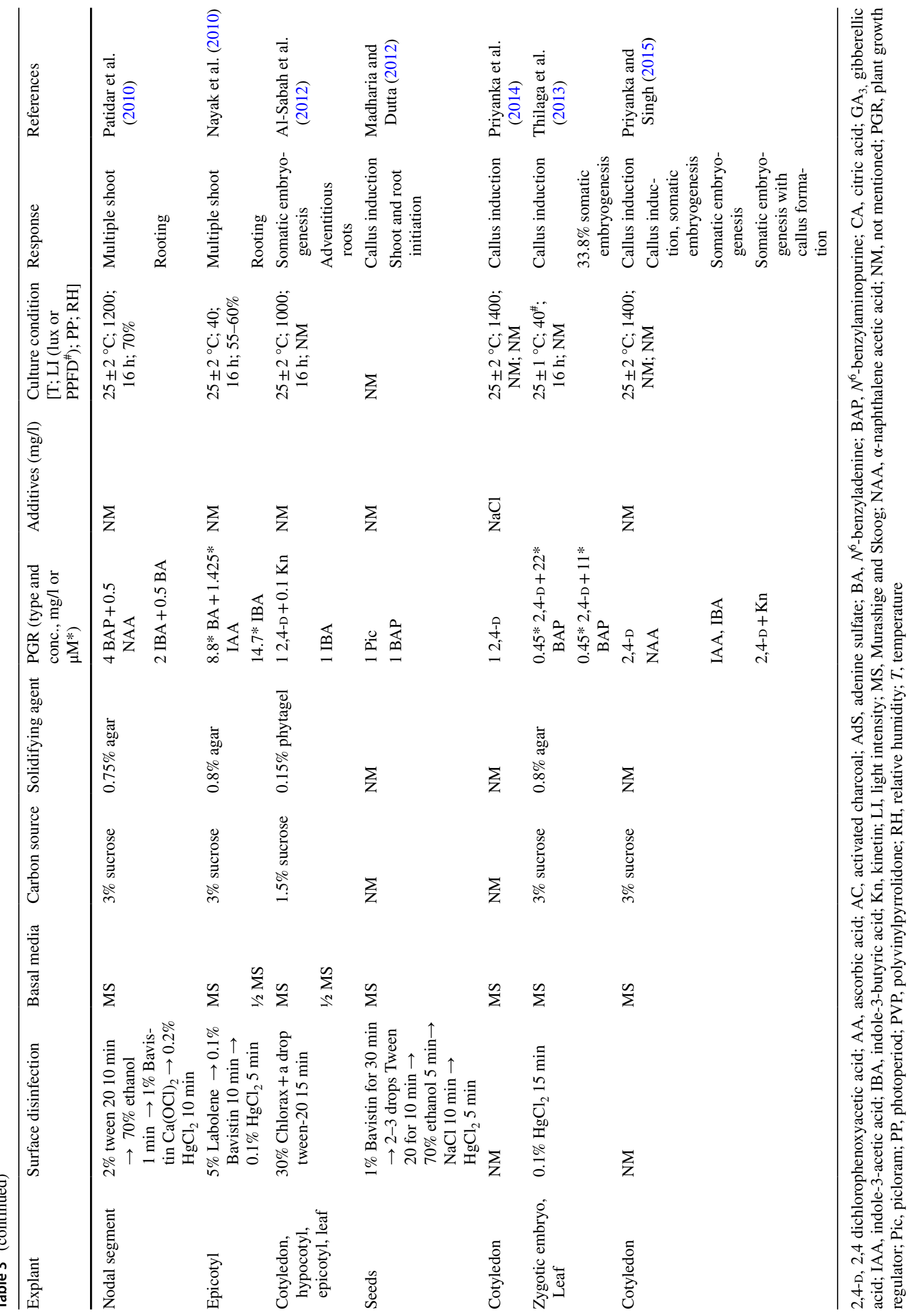


Thilaga et al. 2013; Priyanka and Singh 2015). Hypocotyls, epicotyls, and zygotic embryos are found to be more promising than leaf for indirect somatic embryogenesis. Other explants such as root and root shoot nodes were also reported to be used (Gour and Kant 2009).

\section{Procedures for disinfection of explants}

After selection of explant, surface disinfection of the explant to reduce contamination is the next determining step. The concentration and duration of disinfection are influenced by the type and stage of explant; otherwise, they may exert some unfavorable influence on the growth and development of the explant. In the case of E. officinalis, 2-3 drops of Tween-20 for 5-10 min, subsequently $0.1 \%(w / v)$ mercuric chloride $\left(\mathrm{HgCl}_{2}\right)$ treatment for 5 min with successive washing with sterile water was commonly followed. Among the array of explants used, nodal segment proved an explant of choice owing to their freshness (and greenish nature) even following $\mathrm{HgCl}_{2}$ treatment but at the cost of latent contamination and phenolic leaching. Most of shoot cultures of $E$. officinalis showed higher fungal infection with low bacterial contamination (Goyal and Bhadauria 2008). Reports have mentioned that the survival percentage of explants increases when they were dipped in $\mathrm{HgCl}_{2}$ for lesser time. On the other hand, an increase in concentration $(0.5 \%$ instead of $0.1 \%)$ and duration of $\mathrm{HgCl}_{2}$ treatment resulted in browning and eventual death of explants, and in such situation, sodium hypochloride solution appeared to be a better alternative to control the infection rate (up to 90\%) (Goyal and Bhadauria 2008). Yet, the use of $\mathrm{HgCl}_{2}$ was quite frequent and remained most effective controller of contaminations during in vitro establishment of E. officinalis. Some the researchers used 2\% ( $v / v)$ extran (Verma and Kant 1999) and 5\% labolene (Nayak et al. 2010) instead of Tween 20 prior to treating with $\mathrm{HgCl}_{2}$. Some have used 0.1-1.0\% (w/v) Bavistin either before or after Tween 20 treatment. In addition, the use of freshly prepared chlorine water for endosperm treatment prior to its inoculation was reported too (Sehgal and Khurana 1985). One report cited the use of antioxidants such as ascorbic acid, citric acid and polyvinylpyrrolidone (PVP) for explant treatment before inoculation to check the release of phenolic compounds (Goyal and Bhadauria 2008).

\section{Basal nutrient medium}

The basal medium serves as the source of both macronutrients and micronutrients to the explant under in vitro condition (Gantait and Panigrahi 2018). It also provides vitamins and other organic components required for the growth and development of plants. Almost all researchers have used Murashige and Skoog (MS) (Murashige and Skoog 1962) medium for various experiments in E. officinalis (Sehgal and Khurana 1985; Gupta et al. 1994; Verma and Kant 1999; Mishra and Pathak 2001; Mishra et al. 2006; Goyal and Bhadauria 2008; Gour and Kant 2009; Patidar et al. 2010; Nayak et al. 2010; Al-Sabah et al. 2012; Madharia and Dutta 2012; Priyanka et al. 2014; Thilaga et al. 2013; Priyanka and Singh 2015). Many have reported that half-strength MS medium was effective for rooting in E. officinalis (Verma and Kant 1999; Mishra et al. 2006; Gour and Kant 2009; Nayak et al. 2010; Al-Sabah et al. 2012). The use of liquid MS medium in full-strength was found to be effective especially during the root induction of in vitro shoots (Sehgal and Khurana 1985). In some instances, Gamborg's B5 medium (Gamborg et al. 1968) and woody plant medium (WPM) (Lloyd and McCown 1981) were also used by Goyal and Bhadauria (2008), but found incomparable to the promising results of MS medium; nonetheless, least amount of phenol leaching was found in WPM.

\section{Carbon source}

Carbon is one of the major constituents of the living cells and plays an important role in plant metabolism. It plays a major role in energy production for the functioning of plant cells and also acts as an osmotic regulator in the nutrient medium (Gantait and Kundu 2017). Sucrose was commonly used as the carbon source in the nutrient medium but the concentration may vary. Generally, 3\% (w/v) sucrose was used by most of the researchers (Mishra and Pathak 2001; Mishra et al. 2006; Patidar et al. 2010; Nayak et al. 2010; Thilaga et al. 2013; Priyanka and Singh 2015). For two instances, $2 \%$ or even as low as $1.5 \%$ sucrose was used for in vitro regeneration of multiple shoots (Sehgal and Khurana 1985; Al-Sabah et al. 2012). In another instance, $1.5 \%$ sucrose was used for rooting of regenerated shoots (Verma and Kant 1999). However, the use of table sugar instead of laboratory-grade sucrose for cost reduction was reported to be useful too; and it was also reported that a higher number of shoot and root induction, and increased root length of $E$. officinalis were recorded in medium containing table sugar rather than other alternatives (Gour and Kant 2011).

\section{Physical conditions of growth room}

Physical conditions for instance, temperature, light intensity, photoperiod, and relative humidity play a major role in the growth and development of explant during micropropagation. They have to be artificially controlled according to the requirement of the species. Temperature plays a vital role in the metabolic activities of the cells. For in vitro regeneration of E. officinalis, the temperature was maintained at $25 \pm 2{ }^{\circ} \mathrm{C}$ as cited in most of the reports (Sehgal and Khurana 1985; Mishra and Pathak 2001; Goyal and Bhadauria 2008; Patidar et al. 2010; Nayak et al. 2010; Al-Sabah et al. 2012; Priyanka 
et al. 2014; Thilaga et al. 2013; Priyanka and Singh 2015). However, maintenance of in vitro cultures at a temperature of as high as $28 \pm 2{ }^{\circ} \mathrm{C}$ was also reported (Gupta et al. 1994). Light intensity and photoperiod are necessary for the plant, as light is required to carry out photosynthesis. From the compiled reports, it was noted that cultures of E. officinalis were maintained under a photoperiod of $16 \mathrm{~h}$ (Gupta et al. 1994; Verma and Kant 1999; Mishra and Pathak 2001; Goyal and Bhadauria 2008; Gour and Kant 2009; Patidar et al. 2010; Nayak et al. 2010; Al-Sabah et al. 2012; Thilaga et al. 2013) but the intensity of light varies from 1000 to $3000 \mathrm{~lx}$ or maintained at $40 \mu \mathrm{mol} / \mathrm{m}^{2} / \mathrm{s}$ (Nayak et al. 2010; Thilaga et al. 2013). Maintaining relative humidity (RH) of the culture room is also vital as high relative humidity can result in hyperhydricity of cells and contamination in the cultures (Gantait and Kundu 2017). Cultures of E. officinalis are maintained at 50-60\% RH (Sehgal and Khurana 1985; Verma and Kant 1999; Mishra and Pathak 2001; Nayak et al. 2010); whereas, maintenance of cultures at RHs of $<45 \%$ or $>65 \%$ was also reported (Gupta et al. 1994; Patidar et al. 2010).

\section{Plant growth regulators}

Along with the basal medium and carbon source, PGRs play a major role in the development of plant cells. Major plant growth regulators are auxin, gibberellin and cytokinin. Cytokinin and auxin ratio determines the shoot and root development as well as callus formation. Gibberellin is generally used to break dormancy and initiate seed germination. Use of different PGRs by various researchers for in vitro propagation of E. officinalis has been summarized (Table 3).

\section{Direct regeneration}

Direct regeneration of shoots and roots is achieved by supplementing the culture medium with cytokinin and auxin. Generally higher cytokinin than auxin promotes shoot development and higher auxin than cytokinin promotes rooting. Different cytokinins like $\mathrm{N}^{6}$-benzylaminopurine (BAP) and Kinetin (Kn) have been reported for shoot regeneration but BAP stands out to be most used and gives promising results when used alone or with auxin. Enriching the media with BAP (1-4 mg/l) alone for shoot proliferation was reported by a number of researchers (Verma and Kant 1999; Gour and Kant 2009; Madharia and Dutta 2012). Various combinations for multiple shoot proliferation have also been reported in E. officinalis, such as, BAP + NAA (Verma and Kant 1999; Patidar et al. 2010), BAP + indole-3-butyric acid (IBA) (Goyal and Bhadauria 2008), $\mathrm{N}^{6}$-benzyladenine (BA) + indole-3-acetic acid (IAA) (Nayak et al. 2010). Combination of $\mathrm{Kn}$ and $\mathrm{GA}_{3}$ has been reported (Mishra and Pathak 2001; Mishra et al. 2006) for multiple shoot generation. For regeneration of roots, use of various auxins such as NAA and IBA was reported but in majority of the cases, IBA was supplemented alone (Verma and Kant 1999; Gour and Kant 2009; Nayak et al. 2010; Al-Sabah et al. 2012). Combination of IBA with NAA or sole application of NAA for rooting was reported in fewer instances (Sehgal and Khurana 1985; Mishra et al. 2006). Various additives such as ascorbic acid, citric acid and PVP were also supplemented in the media to check the leaching of phenolic compounds (Gupta et al. 1994; Verma and Kant 1999).

\section{Callus-mediated regeneration}

Callus induction: A callus is an unorganized and unspecialized mass of tissue as a result of a wound on the plant surface. When a basal medium is supplemented with appropriate PGRs, it gives rise to callus, which further differentiated into whole plantlets (Mitra et al. 2020). From the compiled reports on in vitro propagation of $E$. officinalis, it was observed that when endosperm, hypocotyls, epicotyls, embryo, and leaf were used as explant and inoculated in sole 2,4 dichlorophenoxyacetic acid (2,4-D) enriched medium (Gupta et al. 1994; Verma and Kant 1999; Priyanka et al. 2014; Priyanka and Singh 2015), the explants induced calli and further differentiated into shoot and root buds. However, the addition of BAP with 2,4-D $(0.45 \mu \mathrm{M} 2,4-\mathrm{D}+22 \mu \mathrm{M}$ BAP) was reported to induce calli from zygotic embryo and leaf explants (Thilaga et al. 2013). Use of $1 \mathrm{mg} / \mathrm{l}$ picloram (Pic)-supplemented media as an alternative of 2,4-D was effective during induction and proliferation of embryogenic calli (Madharia and Dutta 2012). Similarly, callus was induced from endosperm when the same was inoculated in 2,4-D-free medium fortified by $0.2 \mathrm{mg} / \mathrm{l} \mathrm{BAP}$ and $0.1 \mathrm{mg} / \mathrm{l}$ IAA (Sehgal and Khurana 1985). From the concerned reports, it was evident that calli were induced mainly in 2,4-D-enriched media but there were some cases wherein Pic or BAP:IAA was useful.

Regeneration from callus When the calli were transferred into cytokinin and auxin-rich media, they were differentiated into shoots and roots, respectively. When they were subcultured on media enriched with either BAP or Kin or both, induction of shoot buds were observed. For instance, in $0.2 \mathrm{mg} / \mathrm{l} \mathrm{BAP}+0.1 \mathrm{mg} / \mathrm{l} \mathrm{IAA}$, shoot regeneration was reported but failed to initiate roots. However, rooting of regenerated shoots was achieved in liquid MS medium supplemented with $0.002 \mathrm{mg} / \mathrm{l} \mathrm{NAA} \mathrm{(Sehgal} \mathrm{and} \mathrm{Khurana} \mathrm{1985)}$ or MS medium with $2 \mathrm{mg} / \mathrm{l}$ IBA, resulting in $60-80 \%$ of rooting (Verma and Kant 1999). Higher concentration of BAP $(1-3 \mathrm{mg} / \mathrm{l} \mathrm{BAP})$ was also reported to be effective in differentiation of callus into shoots (Verma and Kant 1999; Madharia and Dutta 2012). BAP along with Kin (3 mg/l 
$\mathrm{BAP}+2 \mathrm{mg} / \mathrm{l} \mathrm{Kin}+0.1$ 2,4-D) was used for more effective shoot formation from callus (Gupta et al. 1994).

\section{Somatic embryogenesis}

Somatic embryo induction Somatic embryogenesis is the development of an embryo from somatic cells of the plant under suitable conditions. It plays a vital role in woody plants for clonal propagation, cryopreservation, and can also be beneficial towards synthetic seed production for germplasm exchange (Gantait et al. 2018). Somatic embryogenesis (direct as well as indirect via. callus) was reported using basal MS media fortified by $1 \mathrm{mg} / 1$ 2,4-D and $0.1 \mathrm{mg} / \mathrm{l} \mathrm{Kn}$ which further develops to shoot and root (Al-Sabah et al. 2012). However, as high as $33.8 \%$ somatic embryogenesis was obtained on MS media fortified by $0.45 \mu \mathrm{M} 2,4-\mathrm{D}$ and $11 \mu$ M BAP (Thilaga et al. 2013). In that report, a number of developmental stages were exhibited when embryogenic callus along with somatic embryos were cross-sectioned and studied. Most of the somatic embryos appeared as cup-like structure at the peripheral region of calli. Direct somatic embryogenesis was obtained in media enriched with IAA and IBA and indirect via callus was obtained in MS media fortified with 2,4-D and Kn (Priyanka and Singh 2015). From the above reports it is evident that 2,4-D-enriched media resulted in somatic embryogenesis in E. officinalis in the majority of the instances.

Regeneration from somatic embryos To date, there are three reports on regeneration from somatic embryogenesis in E. officinalis. Regeneration of plantlets from somatic embryos was seen in PGR-free MS medium (Al-Sabah et al. 2012; Priyanka and Singh 2015) but only one report cited the use of ABA and Kin (3.78 $\mu \mathrm{M} \mathrm{ABA}$ or $0.46 \mu \mathrm{M}$ Kin) for regeneration from somatic embryos (Thilaga et al. 2013). However, no specific stage of somatic embryo was mentioned that resulted in successful regeneration.

\section{Acclimatization}

Acclimatization involves the transfer of in vitro plantlets to the soil and evaluates the survival percentage of the micropropagated plants. The ultimate aim always remains to assess the performance of the in vitro plants in the natural environment. A handful of reports are there on the acclimatization of E. officinalis plantlets in various combinations of soil, sand and compost. Acclimatization of plantlets was successfully achieved in autoclaved sand + soil + farmyard manure mixed either in 1:1:1 $(\mathrm{v} / \mathrm{v})$ ratio or in 6:2:1 (Mishra et al. 2006; Thilaga et al. 2013). Sand + peatmoss + humus mixed in 1:1:1 ratio along with spraying of Bavistin ${ }^{\circledR}$ was also effective for this purpose (Al-Sabah et al. 2012). The use of sterile cocopeat mixed with Bavistin ${ }^{\circledR}$ solution
(Madharia and Dutta 2012) or simple soil + soilrite (3:1) mixture (Verma and Kant 1999) were sufficient to exert significant survival rate during acclimatization. Likewise, as high as $80 \%$ survival rate of acclimatizing plantlets was reported even in ordinary garden soil (Nayak et al. 2010).

\section{Production of secondary metabolites from plant parts}

Secondary metabolites are compounds that are not involved in the growth and development of a plant but are involved in the interaction of plant with its environment (Pagare et al. 2015). Such compounds generally provide protection against biotic and abiotic stresses. Some are even used as drugs, dyes, flavors, etc. that increase their economic value. In $E$. officinalis, secondary metabolites in the form of phenolic compounds are responsible for its antioxidant properties and were estimated to be $439.9 \mathrm{mg} / \mathrm{g}$ of fruit powder when the ethyl acetate fraction was subjected to Sephadex LH-20 chromatography and reverse-phase HPLC (Liu et al. 2008). Another report cited the total phenolic content of ethanol extract of E. officinalis fruit to be $362.43 \pm 11.22 \mathrm{mg} \mathrm{GAE} / \mathrm{g}$ (Gallic acid equivalent) and total flavonoid content to be $6.40 \pm 0.88 \mathrm{mg} \mathrm{QE} / \mathrm{g}$ (quercetin equivalent) (Pientaweeratch et al. 2016). In fresh fruit aqueous extract of E. officinalis, the total phenolic content was determined to be $59.18 \pm 2.91 \mathrm{mg}$ GAE/g by Folin-Ciocalteu assay, total flavonoid content was estimated to be $38.50 \pm 2.84 \mathrm{mg} \mathrm{CE} / \mathrm{g}$ (catechin equivalent) by aluminum chloride colorimetric assay and total tannin content was estimated to be $44.28 \pm 3.09 \mathrm{mg} \mathrm{TAE} / \mathrm{g}$ (tannic acid equivalent) using spectrophotometry (Gunti et al. 2019). However, there is scanty of reports on production or extraction of secondary metabolites from in vitro culture of E. officinalis, wherein such plant tissue culture-based approaches might be quite useful to enhance the production of desirable secondary metabolites (emblicanin-A and -B or tannins in this case) of pharmaceutical importance.

\section{Molecular marker-based biotechnological interventions}

The majority of studies on molecular markers in E. officinalis, to date, mainly focused on random amplified polymorphic DNA (RAPD), which is a widely adopted method in DNA fingerprinting investigation for molecular taxonomy, genotypic differentiation, and other applications (Table 4). Dnyaneshwar et al. (2006) have studied eleven cultivars of E. officinalis for the identification of their species on the basis of RAPD-sequence characterized amplification region (SCAR) markers. Bharmauria et al. (2010) developed an effective method for DNA isolation from leaf samples of eight $E$. officinalis. The authors used a previously published protocol by Warude et al (2003) with a slight modification

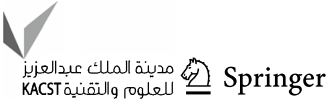




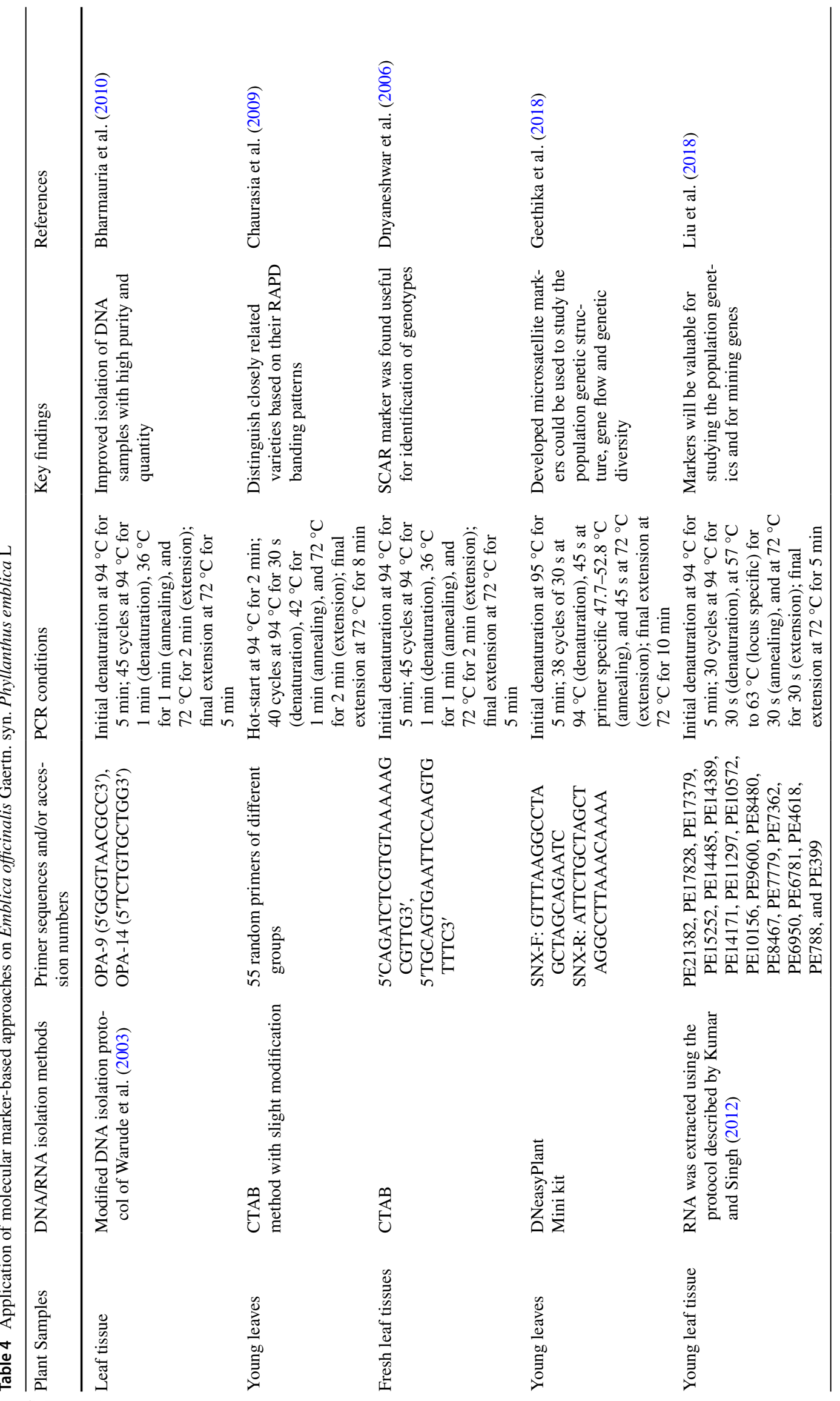




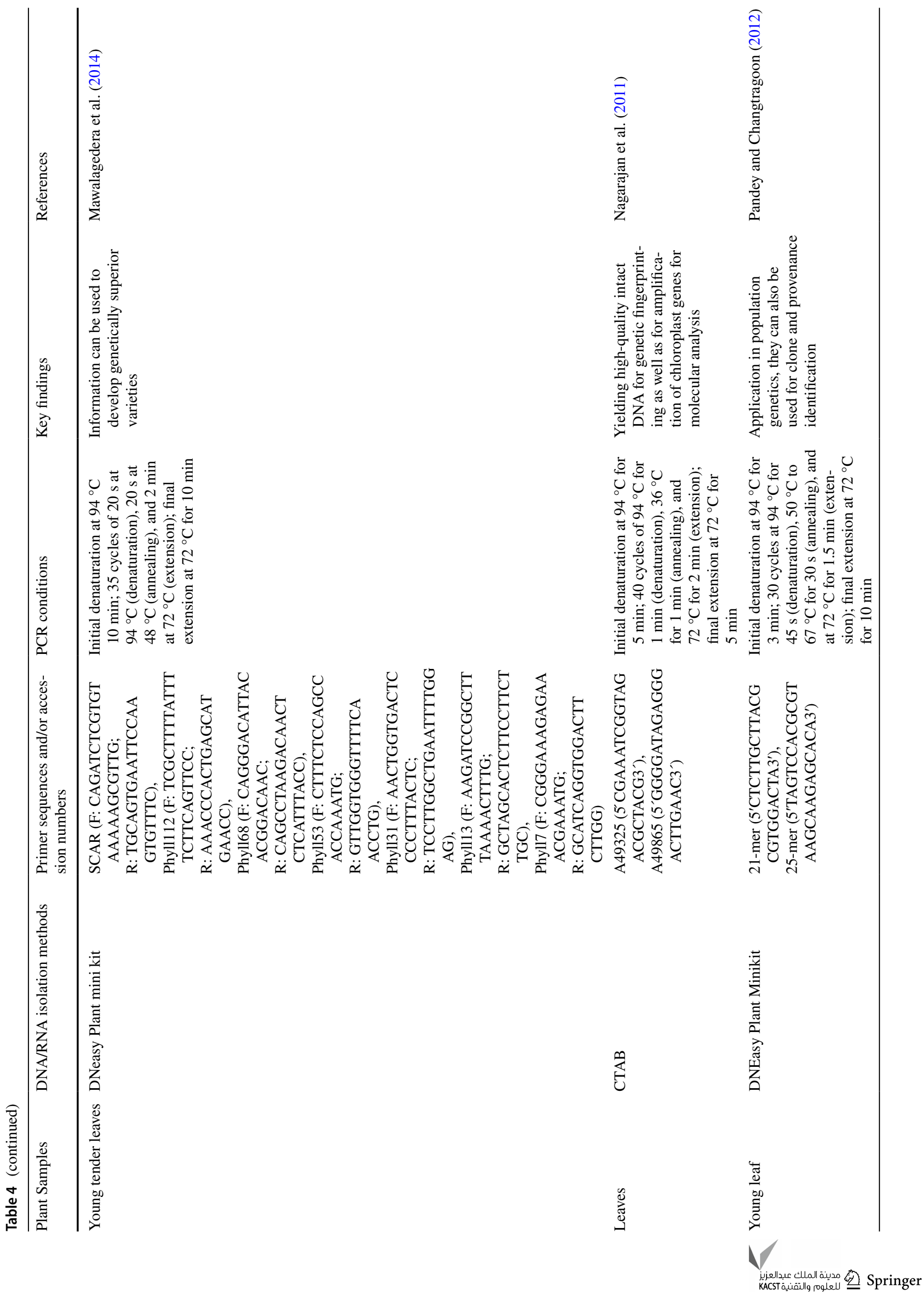




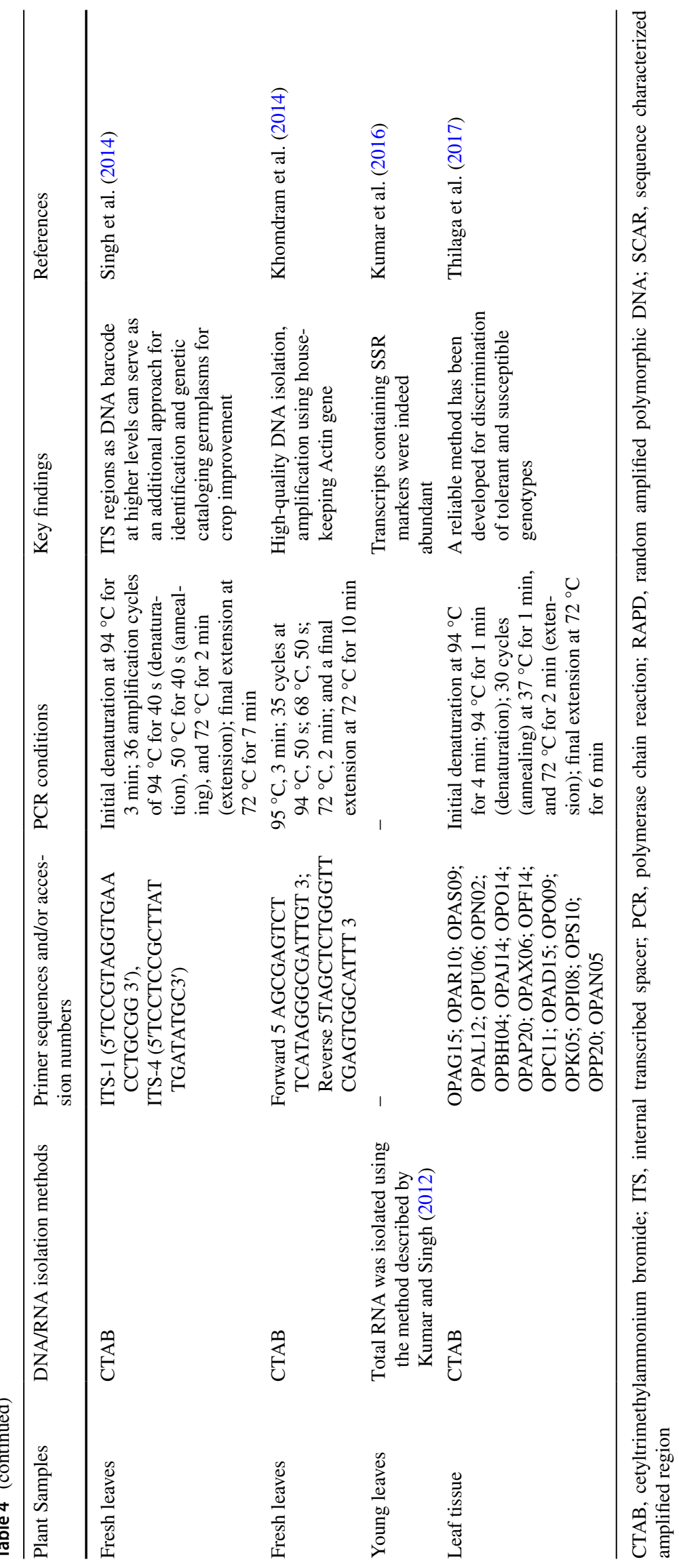


of PVP amount (120 mg) per gram of leaf samples which increased the amount of DNA with good quality; they further concluded that the protocol could be useful for polymorphism and genetic variation studies in E. officinalis or related plants species which is having a high amount of polyphenols and polysaccharides (Bharmauria et al. 2010). The RAPD patterns were obtained from seven varieties of $E$. officinalis by Chaurasia et al. (2009) and these data could serve as an important input to the traditional method of identification of species variation that only based on morphological traits. A DNA isolation protocol had been developed for genetic fingerprinting studies by Nagarajan et al. (2011) with modification of cetyltrimethylammonium bromide (CTAB) protocol. In this study, authors kept $\mathrm{pH}$ stable during all the steps of DNA isolation by adding $\mathrm{NaOH}$ and finally high quality of DNA was achieved from leaf samples of E. officinalis. Five microsatellites were identified as polymorphic out of six markers developed in E. officinalis. These five microsatellites could be useful for the identification of clones, reproductive biology, and genetic structure in this plant species (Pandey and Changtragoon 2012). It has been reported that $E$. officinalis germplasm showed that remarkably high genetic variability and further reported that putative quantitative trait locus (QTLs) could be used to develop new or novel plant varieties (Mawalagedera et al. 2014). Eight different varieties of E. officinalis were investigated by Singh et al. (2014) to extent of genetic variability and relationship between different plant species based on RADP and rDNA polymorphism for breeding programs. Khomdram et al. (2014) optimized genomic DNA isolation using the CTAB extraction method and PCR amplification of DNA, for nineteen wild fruit species including E. officinalis. Kumar et al. (2016) reported a first time transcript associated with each gene involved in vitamin- $\mathrm{C}$ and flavonoid biosynthesis in E. officinalis, and further authors concluded that this important research could be useful for future functional genomics and molecular studies. Thilaga et al. (2017) developed RAPD markers for discrimination of susceptible and tolerant genotypes of $E$. officinalis against shoot-gall marker (Betousa stylophora swinhoe). Seven related species of $E$. officinalis were evaluated for their genetic diversity using microsatellite markers. The authors further concluded that fifteen markers, which were developed from their study, could be useful for the assessment of genetic variability, gene flow, and population genetic structure of $E$. officinalis or related plant species (Geethika et al. 2018). In another study, Liu et al. (2018) developed expressed sequence tagsimple sequence repeat (EST-SSR) markers (twenty highly polymorphic) for E. officinalis to investigate the gene flow and population genetic structures. The above studies have shown that all the markers developed and investigated for crop improvement and breeding program, however, there is still a wide scope for more intensive studies on the development of reproducible molecular markers (like SCoT, AFLP, SNP, RAMP, etc.) and characterization of E. officinalis germplasms and subsequent their genetic improvement against biotic and abiotic stresses.

\section{Nanotechnology: green synthesis of nanoparticles}

In the recent years, the development of plant-based nanomaterials is significantly increased due to its simple, ecofriendly, and cost-effective approach as compared to the conventional chemical method. The green synthesized method was used for the preparation of eco-friendly silver nanoparticles (AgNPs) at various conditions (temperature, time, reducing agent, and concentrations of silver nitrate $\left(\mathrm{AgNO}_{3}\right)$. For this, E. officinalis extract was used as a reducing agent (Fig. 6). Their size (41.2 nm), shape and structure were characterized by transmission electron microscopy (TEM), X-ray diffraction (XRD), scanning electron microscopy (SEM), and UV-Vis spectrophotometer (Mookriang et al. 2013). A simple, eco-friendly, low-cost, green synthesis of silver nitrate nanoparticle using $E$. officinalis fruit extract as a capping, stabilizing, and reducing agent was reported by Masum et al. (2019). Further, as-prepared AgNPs were characterized
Fig. 6 Diagram representing the green synthesis of metal/ metal oxide nanoparticles from Emblica officinalis Gaertn. syn. Phyllanthus emblica L. extracts, their characterization and effects against microorganisms (Source: unpublished photograph of Sandeep Kumar Verma and Saikat Gantait)

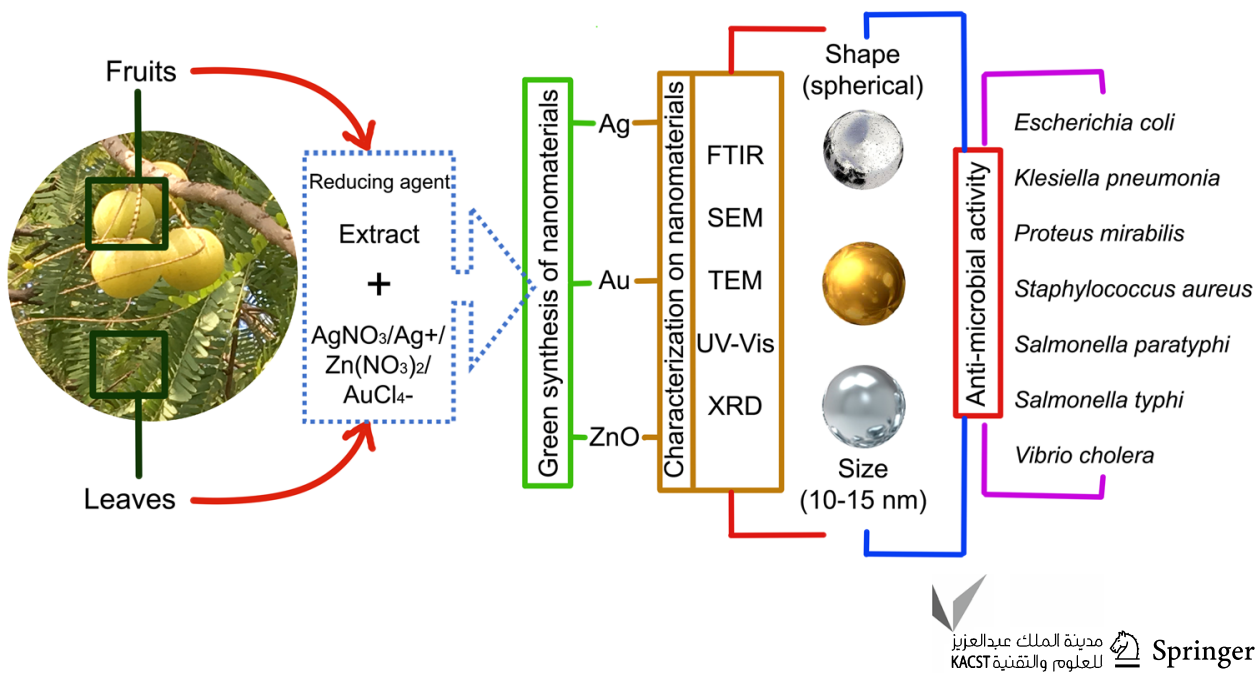


by different methods including Fourier transform spectroscopy (FTIR), TEM, X-ray diffraction (XRD), SEM, and energy-dispersive X-ray (EDX) (Fig. 6). The AgNPs were spherical in shape with particle size ranged 19.8-92.4 nm and the average diameter was $39 \mathrm{~nm}$. Moreover, different concentration $(5,10,20$, and $30 \mu \mathrm{g} / \mathrm{ml})$ of AgNPs used for antimicrobial (acidovorax oryzae strain RS-2 of rice bacterial brown stripe) activity and compared with control (E. officinalis fruit extract) group and $20 \mu \mathrm{g} / \mathrm{ml} \mathrm{AgNO}_{3}$ showed remarkable antimicrobial activity (Masum et al. 2019). Maria et al. (2019) reported a facile, green synthesis method using E. officinalis leaf extract. The as-prepared zinc oxide nanoparticles (ZnONPs) were further characterized by XRD, FTIR, TEM, UV-Vis diffuse reflectance spectroscopy, filed emission-SEM, and photoluminescence measurements. ZnONPs are quasi-spherical with a particle size of 30-40 nm. The as-synthesized ZnONPs showed growth inhibitory effects against Escherichia coli, Vibrio cholerae, and Salmonella paratyphi (Maria et al. 2019). The green fabrication of AgNPs using fruit residue of E. officinalis was reported by Nayagam et al. (2018). The as-synthesized AgNPs further characterized by various techniques including UV-Vis, FTIR, XRD and SEM. The antimicrobial activities of AgNPs (spherical in shape) showed maximum growth inhibition of Proteus mirabilis, Staphylococcus aureus, Salmonella typhi, and Vibrio cholera (Fig. 6). The rapid, green route of fabrication of silver $(\mathrm{Ag})$ and gold $(\mathrm{Au})$ NPs using E. officinalis fruit extract (as a reducing agent) was demonstrated by Ankamwar et al. (2005). TEM analysis revealed that $\mathrm{Ag}$ and $\mathrm{Au}$ nanoparticles size ranged from 10 to $20 \mathrm{~nm}$ and 15 to $25 \mathrm{~nm}$, respectively. In another study, AgNPs were synthesized from a simple, fast, eco-friendly, and green synthesis approach using E. officinalis fruit extract. SEM analysis result showed that AgNPs spherical shaped and particle size ranges between 19 and $45 \mathrm{~nm}$ with an average size of $30 \mathrm{~nm}$. The as-prepared AgNPs exhibited remarkable antibacterial effects including Staphylococcus aureus and Klebsiella pneumonia bacteria (Renuka et al. 2020). These studies provide evidence about green synthesized nanomaterials can be potential candidates for antibacterial activities. Furthermore, these nanomaterials could be useful agents for biotechnological and agricultural applications.

\section{Conclusion}

The achievements in the field of in vitro propagation-based research on E. officinalis, since the 1980s till 2020, have been highlighted in this review. There are merely a few reports on the direct, indirect organogenesis and somatic embryogenesis of this tree with high medicinal value; and there is still a lot of research work that still needs to be explored on the concerned topic (Fig. 5). For instance, the use of different basal media such as Eeuwen's medium (Eeuwen 1976), Nitsch and Nitsch medium (Nitsch and Nitsch 1969), Schenk and Hildebrandt medium (Schenk and Hildebrandt 1972), White's medium (White 1963), etc. can also be attempted as there is a report on lesser leaching of phenolic compounds and higher shoot proliferation frequency in these media. For carbon source, only sucrose was taken into account for $E$. officinalis; whereas, other derivatives like fructose, galactose, maltose, and other complex polysaccharides or sugar alcohols like mannitol can also be considered. There is no report on the use of urea derivatives like thidiazuron and topolin group (like meta-topolin) of growth regulators in E. officinalis as their use can serve as better replacements of regular cytokinins (like BA or Kn) for direct and indirect organogenesis. Synthetic derivatives like dicamba that have auxin-like activity can also be explored to attain highfrequency callus induction. The use of additives like adenine sulfate and activated charcoal for enhancing shoot and root growth, respectively, is yet to be tested on this tree. The concentration of ascorbic acid, citric acid and PVP in the basal media needs to be standardized for minimizing the leaching of phenolic compounds and browning of tissues. The enhancement of core secondary metabolite production in $E$. officinalis needs to be addressed adequately. Escalated production of emblicanin-A and emblicanin-B can be attained via cell suspension culture, added with elicitors of biotic and abiotic origin. Genetic transformation like hairy root culture via Agrobacterium rhizogenes serves as a promising tool for enhancing the metabolite profile of any medicinal plant (Gantait and Mukherjee 2021a) and this strategy is yet to be explored in E. officinalis. Other novel genetic transformation approaches like electroporation (direct) method or indirect via vector mediated using $A$. tumifaciens or other related vectors are left unexplored to date. Polyploidy can also be attempted towards enhancing secondary metabolites (Gantait and Mukherjee 2021b), which can be achieved via the use of colchicine and other anti-mitotic chemicals like oryzalin or trifluralin. In vitro mutagenesis can also serve as a viable option for the amelioration of emblicanin-A and -B biosynthesis via the use of chemical like ethyl methane sulphonate and ethidium bromide or using physical mutagens such as ultra-violet or gamma radiation. Owing to its nutritional and pharmaceutical values, nanotechnology can also be explored in the near future. Henceforth, this review brings forth all the in vitro biotechnological work done in $E$. officinalis till date and cites the significant shortcomings that may serve as a base for further advanced experimental work.

\section{Prospect of $E$. officinalis under cutting-edge biotechnological interventions}

In addition to all the aforementioned research investigations, numerous research studies are required for the evaluation 
through the appropriate interventions of some biotechnological tools such as transgenic technology, marker-assisted selection, quantitative trait loci (QTL), functional genomics, RNA interference, proteomics, etc. These tools easily facilitated the route for booming utilization and amalgamation of different scientific areas, which positively necessities the deliverance of quality research for tree biotechnologies. Apart from this, system-based nano-technological instruments concentrate and deal with some important issues (Verma et al. 2018, 2019) related to regular farming of varieties of trees species. This eventually impacts and helps in the enhanced transformation of agroforestry sector. Successful and prosperous growth and incorporation of such scientific areas leads to the enormous hammer in different ways. Finally, this phenomenon generates new, fruitful, and essential data by providing necessary supports as well as contributions in electrifying projections and scenarios to create opportunities in biotechnological improvement of tree species at the global level.

Acknowledgments Authors acknowledge the University e-library assistance from Bidhan Chandra Krishi Viswavidyalaya, West Bengal, India. We are further thankful to the anonymous reviewer(s) and the editor of this article for their critical comments and suggestions on the manuscript.

Author contributions SG conceived the idea of the review and surveyed the literature; SG, MM, SB, SKV drafted the manuscript equally; SG scrutinized and corrected the manuscript to its final version. All the authors read and approved the final version of the manuscript prior to its submission.

Funding None.

\section{Compliance with ethical standards}

Conflict of interest All author(s) declare that they have no conflict of interest.

Ethical approval This article does not contain any studies with human participants or animals performed by any of the authors.

Open Access This article is licensed under a Creative Commons Attribution 4.0 International License, which permits use, sharing, adaptation, distribution and reproduction in any medium or format, as long as you give appropriate credit to the original author(s) and the source, provide a link to the Creative Commons licence, and indicate if changes were made. The images or other third party material in this article are included in the article's Creative Commons licence, unless indicated otherwise in a credit line to the material. If material is not included in the article's Creative Commons licence and your intended use is not permitted by statutory regulation or exceeds the permitted use, you will need to obtain permission directly from the copyright holder. To view a copy of this licence, visit http://creativecommons.org/licenses/by/4.0/.

\section{References}

Agrawal RC, Sharma R, Maheshwari SK (2012) Antimutagenic and wound healing activity of Emblica officinalis extract in Swiss Albino mice. Int J Sci Eng Res 3:1-12

Ali SK, Hamed AR, Soltan MM, Hegazy UM, Elgorashi EE, El-Garf IA, Hussein AA (2013) In-vitro evaluation of selected Egyptian traditional herbal medicines for treatment of alzheimer disease. BMC Complement Altern Med 13:121

Al-Sabah L, Sudhersan C, Jibi-Manuel S (2012) Somatic embryogenesis and plantlet regeneration in amla. Am Eurasian J Sustain Agric 6:417-421

Ankamwar B, Damle C, Ahmad A, Sastry M (2005) Biosynthesis of gold and silver nanoparticles using Emblica officinalis fruit extract, their phase transfer and transmetallation in an organic solution. J Nanosci Nanotechnol 5:1665-1671

Ashwlayan VD, Singh R (2011) Reversal effect of Phyllanthus emblica (Euphorbiaceae) Rasayana on memory deficits in mice. Int J Appl Pharm 3:10-15

Asmilia N, Sutriana A, Aliza D, Sudril N (2020) Anti-inflammatory activity of ethanol extract from malacca leaves (Phyllanthus emblica) in carrageenan induced male mice. In: E3S Web Conf, vol 151, pp 01066.

Awasthi OP, Singh IS, More TA (2009) Performance of intercrops during establishment phase of aonla (Emblica officinalis) orchard. Ind J Agri Sci 79:587-591

Bafna PA, Balaraman R (2005) Anti-ulcer and anti-oxidant activity of pepticare, a herbomineral formulation. Phytomedicine $12: 264-270$

Baliga MS, Shivashankara AR, Thilakchand KR, Baliga-Rao MP, Palatty PL, George T, Rao S (2019) Hepatoprotective effects of the Indian gooseberry (Emblica officinalis Gaertn): a revisit. In: Watson RR, Preedy VR (eds) Dietary interventions in liver disease. Academic Press, Cambridge, pp 193-201

Banyal SK, Banyal AK (2019) Refinement of propagation techniques of aonla (Emblica officinalis Gaertn.) in north western himalayan region. Int J Bio-resource Stress Manag 10:87-91

Barathkumar TR (2019) Studies on influence of different seed treatments on dormancy breaking in aonla (Phyllanthus embolic L.). J Pharmacogn Phytochem 2019:131-133

Bhagat M (2014) Indian gooseberry (Emblica officinalis): Pharmacognosy review. In: Gupta A, Kaul VK (eds) Utilisation and management of medicinal plants, vol 2. Daya Publishing House, New Delhi, pp 471-487

Bharmauria V, Verma V, Narang N, Sharma S (2010) Efficient DNA isolation from Emblica officinalis for effective PCR. Sci Res Essay 5:105-109

Bhattacharya A, Chatterjee A, Ghosal S, Bhattacharya SK (1999) Antioxidant activity of active tannoid principles of Emblica officinalis (amla). Indian J Exp Biol 37:676-680

Chatterjee A, Chatterjee S, Biswas A, Bhattacharya S, Chattopadhyay S, Bandyopadhyay SK (2012) Gallic acid enriched fraction of Phyllanthus emblica potentiates indomethacin-induced gastric ulcer healing via e-NOS-dependent pathway. Evid Based Complem Alternat Med 2012:487380

Chaudhary N, Sabikhi L, Hussain SA, Kumar R, Choudhary U (2020) Emblicanin rich Emblica officinalis encapsulated double emulsion and its antioxidant stability during storage. Eur J Lipid Sci Tech 122:1900316

Chaurasia AK, Subramaniam VR, Krishna B, Sane PV (2009) RAPD based genetic variability among cultivated varieties of Aonla (Indian Gooseberry, Phyllanthus emblica L.). Physiol Mol Biol Plants 15:169-173

Chiranjeevi MR, Muralidhara BM, Sneha MK, Hongal S (2017) Effect of growth regulators and biofertilizers on germination and

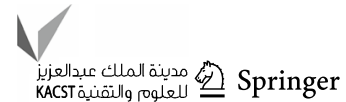


seedling growth of aonla (Emblica officinalis Gaertn). Int J Curr Microbiol App Sci 6:1320-1326

Chularojmontri L, Suwatronnakorn M, Wattanapitayakul SK (2013) Phyllanthus emblica L. enhances human umbilical vein endothelial wound healing and sprouting. Evid Based Complem Alternat Med 2013:720728

Das DK, Chaturvedi OP, Jha RK, Kumar R (2011) Yield, soil health and economics of aonla (Emblica officinalis Gaertn.)-based agrihorticultural systems in eastern India. Curr Sci 101:786-790

Dhanalakshmi S, Devi RS, Srikumar R, Manikandan S, Thangaraj R (2007) Protective effect of Triphala on cold stress-induced behavioural and biochemical abnormalities in rats. Yakugaku Zasshi 127:1863-1867

Dinesh M, Roopan SM, Selvaraj CI, Arunachalam P (2017) Phyllanthus emblica seed extract mediated synthesis of PdNPs against antibacterial, heamolytic and cytotoxic studies. J Photochem Photobiol B Biol 167:64-71

Dnyaneshwar W, Preeti C, Kalpana J, Bhushan P (2006) Development and application of RAPD-SCAR marker for identification of Phyllanthus emblica LINN. Biol Pharm Bull 29:2313-2316

Eeuwen CJ (1976) Mineral requirements for growth and callus initiation of tissue explants excised from mature coconut palms (Cocos nucifera) and cultured in vitro. Physiol Plant 36:23-28

Fatima N, Hafizur RM, Hameed A, Ahmed S, Nisar M, Kabir N (2017) Ellagic acid in Emblica officinalis exerts anti-diabetic activity through the action on $\beta$-cells of pancreas. Eur J Nutr 56:591-601

Gamborg OL, Miller RA, Ojima K (1968) Nutrient requirements of suspension cultures of soyabean root cells. Exp Cell Res 50:151-158

Gantait S, Kundu S (2017) Neoteric trends in tissue culture-mediated biotechnology of Indian ipecac [Tylophora indica (Burm. F.) Merrill]. 3Biotech 7:231

Gantait S, Mukherjee E (2021a) Hairy root culture technology: applications, constraints and prospect. Appl Microbiol Biotechnol 105:35-53

Gantait S, Mukherjee E (2021b) Induced autopolyploidy — a promising approach for enhanced biosynthesis of plant secondary metabolites: an insight. J Genet Eng Biotechnol 19:4

Gantait S, Panigrahi J (2018) In vitro biotechnological advancements in Malabar nut (Adhatoda vasica Nees): achievements, status and prospects. J Genet Eng Biotechnol 16:545-552

Gantait S, El-Dawayati MM, Panigrahi J, Labrooy C, Verma SK (2018) The retrospect and prospect of the applications of biotechnology in Phoenix dactylifera L. App Microbiol Biotechnol 102:8229-8259

Geethika E, Triveni HN, Srirama R, Siva R, Setty S, Ravikanth G (2018) Development and characterization of microsatellite markers for Phyllanthus emblica Linn., important nontimber forest product species. J Genet 97:1001-1006

Ghosal S, Tripathi VK, Chauhan S (1996) Active constituents of Emblica officinalis: part 1-the chemistry and antioxidative effects of two new hydrolysable tannins, Emblicanin A and B. Indian J Chem B 35:941-948

Ghosh SN, Pal PP (2010) Effect of intercropping on plant and soil of Mosambi sweet orange orchard under rainfed conditions. Indian J Hort 67:185-190

Golechha M, Bhatia J, Arya DS (2012) Studies on effects of Emblica officinalis (Amla) on oxidative stress and cholinergic function in scopolamine induced amnesia in mice. J Environ Biol 33:95-100

Gour VS, Kant T (2009) In vitro regeneration in Emblica officinalis from juvenile root-derived callus. J Indian Bot Soc 89:34-36

Gour VS, Kant T (2011) Efficacy of low cost gelling agents and carbon source alternatives during in vitro rooting of Balanites aegyptiaca and Phyllanthus emblica microshoots. Tree For Sci Biotechnol 5:58-60
Goyal D, Bhadauria S (2008) In vitro shoot proliferation in Emblica officinalis var. Balwant from nodal explants. Indian J Biotechnol 7:394-397

Gunti L, Dass RS, Kalagatur NK (2019) Phytofabrication of selenium nanoparticles from Emblica officinalis fruit extract and exploring its biopotential applications: antioxidant, antimicrobial, and biocompatibility. Front Microbiol 10:931

Gupta P, Patni Y, Kant U (1994) In vitro shoot differentiation in Emblica officinalis Gaertn. J Phytol Res 7:171-172

Gupta M, Banerjee D, Mukherjee A (2013) Evaluation of analgesic, antipyretic and anti-inflammatory effects of methanol extract of traditional herbal medicine using rodents. J Pharmacogn Phytother 5:106-113

Jagetia GC, Malagi KJ, Baliga MS, Venkatesh P, Veruva RR (2004) Triphala, an ayurvedic rasayana drug, protects mice against radiation-induced lethality by free-radical scavenging. J Altern Complement Med 10:971-978

Jalal A, Tripathi S, Kumar A (2019) Standardization of propagation techniques in different cultivars of aonla (Emblica officinalis Gaertn). Int J Pure Appl Biosci 7:71-77

Jamaluddin (1978) Cladosporium rot of fruit of Phyllanthus emblica. Proc Natl Acad Sci India-B 48:62

Justin Thenmozhi A, Dhivyabharathi M, William Raja TR, Manivasagam T, Essa MM (2016) Tannoid principles of Emblica officinalis renovate cognitive deficits and attenuate amyloid pathologies against aluminum chloride induced rat model of Alzheimer's disease. Nutr Neurosci 19:269-278

Kalekar SA, Munshi RP, Bhalerao SS, Thatte UM (2013) Insulin sensitizing effect of 3 Indian medicinal plants: an in vitro study. Indian J Pharmacol 45:30-33

Khan KH (2009) Roles of Emblica officinalis in medicine-a review. Bot Res Int 2:218-228

Khomdram S, Barthakur S, Devi GS (2014) Biochemical and molecular analysis of wild endemic fruits of the manipur region of India Int J Fruit Sci 14:253-266

Kim HJ, Yokozawa T, Kim HY, Tohda C, Rao TP, Juneja LR (2005) Influence of amla (Emblica officinalis Gaertn.) on hypercholesterolemia and lipid peroxidation in cholesterol-fed rats. J Nutr Sci 75:65-69

Kumar A, Singh K (2012) Isolation of high quality RNA from Phyllanthus emblica and its evaluation by downstream applications. Mol Biotechnol 52:269-275

Kumar A, Singh A, Dora J (2012a) Essential perspectives for Emblica offcinalis. Int J Pharma Chem Sci 1:11-18

Kumar KS, Bhowmik D, Dutta A, Yadav AP, Paswan S, Srivastava S, Deb L (2012b) Recent trends in potential traditional Indian herbs Emblica officinalis and its medicinal importance. J Pharmacogn Phytochem 1:18-28

Kumar A, Kumar S, Bains S, Vaidya V, Singh B, Kaur R, Kaur J, Singh K (2016) De novo transcriptome analysis revealed genes involved in flavonoid and vitamin $\mathrm{C}$ biosynthesis in Phyllanthus emblica (L.). Front Plant Sci 7:1610

Liu X, Cui C, Zhao M, Wang J, Luo W, Yang B, Jiang Y (2008) Identification of phenolics in the fruit of emblica (Phyllanthus emblica L.) and their antioxidant activities. Food Chem 109:909-915

Liu X, Ma H, Li T, Li Z, Wan Y, Liu X, Fu L (2018) Development of novel EST-SSR markers for Phyllanthus emblica (Phyllanthaceae) and cross-amplification in two related species. Appl Plant Sci 6:e1169

Lloyd G, McCown B (1981) Commercially feasible micropropagation of mountain laurel, Kalmia latifolia, by shoot tip culture. Intl Plant Prop Soc Proc 30:421-427

Madharia P, Dutta AK (2012) Indirect somatic embryogenesis in Emblica: a preliminary study in our research lab. Biosci Biotechnol Res Asia 9:305-308 
Mahata S, Pandey A, Shukla S, Tyagi A, Husain SA, Das BC, Bharti AC (2013) Anticancer activity of Phyllanthus emblica Linn. (Indian Gooseberry): Inhibition of transcription factor AP-1 and HPV gene expression in cervical cancer cells. Nutr Cancer 65:88-97

Maholiya BK, Prasad H, Thakur M, Gupta AK, Solanki SPS (2015) Comparative performance of aonla (Emblica officinalis G.) cultivars under parbhani condition. Int J Bio-resour Stress Manag 6:778-780

Majeed M, Majeed S, Mundkur L, Nagabhushanam K, Arumugam S, Beede K, Ali F (2020) Standardized Emblica officinalis fruit extract inhibited the activities of $\alpha$-amylase, $\alpha$-glucosidase, and dipeptidyl peptidase-4 and displayed antioxidant potential. J Sci Food Agric 100:509-516

Maria A, Mookkaiah R, Elayaperumalc M (2019) Emblica officinalis leaf extract mediated synthesis of zinc oxide nanoparticles for antibacterial and photocatalytic activities. Asian J Green Chem 3:418-431

Masum MMI, Siddiqa MM, Ali KA, Zhang Y, Abdallah Y, Ibrahim E, Qiu W, Yan C, Li B (2019) Biogenic synthesis of silver nanoparticles using Phyllanthus emblica fruit extract and its inhibitory action against the pathogen acidovorax oryzae strain RS-2 of rice bacterial brown stripe. Front Microbiol 10:820

Mathew M, Subramanian S (2014) In vitro screening for anti-cholinesterase and antioxidant activity of methanolic extracts of ayurvedic medicinal plants used for cognitive disorders. PLoS ONE 9:e86804

Mawalagedera SMUP, Janaththani P, Dunuwille SWMB, Perera GAD, Weebadde CK, Wijesundara DSA, Sooriyapathirana SDSS (2014) DNA marker analysis reveals genomic diversity and putative QTL associated with drupe traits in Phyllanthus emblica. Ceylon J Sci (Bio Sci) 43:31-46

Meena AK, Singh A, Rao MM (2010) Evaluation of physicochemical and preliminary phytochemical studies on the fruit of Emblica officinalis Gaertn. Asian J Pharma Clin Res 3:242-243

Mehrotra S, Jamwal R, Shyam R, Meena DK, Mishra K, Patra R, De R, Mukhopadhyay A, Srivastava AK, Nandi SP (2011) AntiHelicobacter pylori and antioxidant properties of Emblica officinalis pulp extract: a potential source for therapeutic use against gastric ulcer. J Med Plant Res 5:2577-2583

Mishra N (1988) Studies on fungi deteriorating stored fruits of Emblica officinalis Gaertn. Int J Tropical Plant Dis 6:95-97

Mishra M, Pathak RK (2001) Effect of nodal position and season on in vitro shoot proliferation in aonla (Emblica officinalis Gaertn.). J Appl Hort 3:103-104

Mishra M, Pati R, Chandra R, Kole C (2006) Clonal micropropagation of Indian gooseberry (Emblica officinalis Gaertn.). Indian J Genet Plant Breed 66:361-362

Mishra M, Shukla N, Chandra R (2011) Aonla. In: Singh HP, Parthasarathy VA, Nirmal Babu K (Eds) Advances in horticulture biotechnology (Vol. 1): regeneration systems of fruit crops, plantation crops and spices, Vol. I, Westville Publishing House, New Delhi, pp 185-190

Mishra SM, Ram D, Pandey A, Meena AK (2017a) Effect of foliar feeding of micronutrients yield of aonla fruits (Emblica officinalis Gaertn). Progressive Res An Int J 12:932-934

Mishra SM, Ram D, Pandey A, Meena AK (2017b) Effect of foliar feeding of micro-nutrients on physico-chemical attributes of aonla (Emblica officinalis Gaertn) cv. Na-7 under high density planting. Int J Curr Microbiol App Sci 6:1951-1957

Mitra M, Gantait S, Mandal N (2020) Coleus forskohlii: advancements and prospects of in vitro biotechnology. Appl Microbiol Biotechnol 104:2359-2371

Mookriang S, Jimtaisong A, Saewan N, Kittigowittana K, Rachtanapun P, Pathawinthranond V, Sarakornsri T (2013) Green synthesis of silver nanoparticles using a vitamin C rich Phyllanthus emblica extract. Adv Mat Res 622-623:864-868

More TA, Samadia DK, Awasthi OP, Hiwale SS (2008) Varieties and hybrids of CIAH. In: Central Institute for Arid Horticulture, Bikaner, Rajasthan, India, p 11

Mukherjee E, Gantait S, Kundu S, Sarkar S, Bhattacharyya S (2019) Biotechnological interventions on the genus Rauvolfia: recent trends and imminent prospects. Appl Microbiol Biotechnol 103:7325-7354

Murashige T, Skoog F (1962) A revised medium for rapid growth and bio assays with tobacco tissue cultures. Physiol Plant 15:473-497

Muthuraman A, Shailja SS, Singla SK (2011) The antiinflammatory potential of phenolic compounds from Emblica officinalis L. in rat. Inflammopharmacol 19:327-334

Mythilypriya R, Shanthi P, Sachdanandam P (2007) Analgesic, antipyretic and ulcerogenic properties of an indigenous formulationKalpaamruthaa. Phytother Res 21:574-578

Nagarajan S, Steephen M, Murugan K, Nair RR, Sethuraman T, Alagar $P$, Ganesh D (2011) Improved protocol for isolation of genomic DNA from leaf tissues of Phyllanthus emblica Gaertn. Iranian J Biotechnol 9:307-313

Nain P, Saini V, Sharma S, Nain J (2012) Antidiabetic and antioxidant potential of Emblica officinalis Gaertn. leaves extract in streptozotocin-induced type-2 diabetes mellitus (T2DM) rats. J Ethnopharmacol 142:65-71

Nallathambi P, Umamaheswari C, Nagaraja A, Dhandar DG (2007) Aonla diseases and management. In: Technical Bulletin, Central Institute for Arid Horticulture, Bikaner, India

Nath V, Singh IS, Kumar S, Pandey AK (1992) Effects of post harvest treatments on shelf life of aonla fruits. Progress Hort 24:79-82

Nath A, Raghunatha P, Joshi SR (2012) Diversity and biological activities of endophytic fungi of Emblica officinalis, an ethnomedicinal plant of India. Mycobiology 40:8-13

Nayagam V, Gabriel M, Palanisamy K (2018) Green synthesis ofsilver nanoparticles mediated by Coccinia grandis and Phyllanthus emblica: a comparative comprehension. Appl Nanosci 8:205-219

Nayak P, Behera PR, Thirunavoukkarasu M, Chand PK (2010) High frequency plant regeneration through adventitious multiple shoot organogenesis in epicotyl explants of Indian gooseberry (Emblica officinalis Gaertn). Sci Hort 123:473-478

Nemmani KV, Jena GB, Dey CS, Kaul CL, Ramarao P (2002) Cell proliferation and natural killer cell activity by polyherbal formulation, Immu-21 in mice. Indian J Exp Biol 40:282-287

Nitsch JP, Nitsch C (1969) Haploid plants from pollen grains. Science 163:85-87

Ojha S, Golechha M, Kumari S, Arya DS (2012) Protective effect of Emblica officinalis (amla) on isoproterenol-induced cardiotoxicity in rats. Toxicol Ind Health 28:399-411

Pagare S, Bhatia M, Tripathi N, Pagare S, Bansal YK (2015) Secondary metabolites of plants and their role: overview. Curr Trend Biotechnol Pharma 9:293-304

Pal S, Ramamurthy A, Rath S, Mahajon B (2017) Healing role of Guduchi [Tinospora cordifolia (Willd.) Miers] and Amalaki (Emblica officinalis Gaertn.) capsules in premature aging due to stress: a comparative open clinical trial. Eur J Med Plant 2:1-3

Pandey M, Changtragoon S (2012) Isolation and characterization of microsatellites in a medicinal plant, Phyllanthus emblica (euphorbiaceae). Am J Bot 99:e468-e469

Pareek S (2010) Aonla (Emblica officinalis Gaertn.)-value added products. In: Peter KV (ed) Underutilized and underexploited horticultural crops. New India Publishing Agency, New Delhi, pp 283-308 
Pareek S, Kitinoja L (2011) Aonla (Emblica officinalis Gaertn.). In: Yahia EM (ed) Postharvest biology and technology of tropical and subtropical fruits, vol 2, 1st edn. Woodhead Publishing, Cambridge, pp 65-99e

Patel SS, Goyal RK (2011) Emblica officinalis Geartn.: a comprehensive review on phytochemistry, pharmacology and ethnomedicinal uses. Res J Med Plant 2011:1-11

Patel P, Singh HS, Mishra A, Ansari SP (2017) Can Emblica officinalis and Tinospora cordifolia supplementation possess immunomodulatory and adaptogenic properties in murrah buffalo calves? Indian J Animal Res 51:506-509

Pathak RK, Pandey D, Singh G, Mishra D (2003) Approaches and strategies for precision farming in aonla. In: Singh HP, Singh G, Singh JC, Samuel, Pathak RK (Eds) Proceedings of National seminar-cum-workshop on hi-tech horticulture and precision farming, CISH, Lucknow, India, pp 176-190

Patidar DK, Tripathi MK, Tiwari R, Baghel BS, Tiwari S (2010) In vitro propagation of Emblica officinalis from nodal segment culture. J Agri Tech 6:245-256

Pientaweeratch S, Panapisal V, Tansirikongkol A (2016) Antioxidant, anti-collagenase and anti-elastase activities of Phyllanthus emblica, Manilkara zapota and silymarin: an in vitro comparative study for anti-aging applications. Pharma Biol 54:1865-1872

Pramyothin P, Samosorn P, Poungshompoo S, Chaichantipyuth C (2006) The protective effects of Phyllanthus emblica Linn. extract on ethanol induced rat hepatic injury. J Ethnopharmacol 107:361-364

Premi BR, Sethi V, Saxena DB (1998) Studies on identification of white specks in cured aonla (Emblica officinalis Gaertn.) fruits. Food Chem 61:9-11

Priyanka KU, Singh KP (2015) Indirect, direct and secondary somatic embryogenesis in Emblica officinalis. Global J Res Anal 4:1-4

Priyanka KU, Rather MI, Deepti Vimala Y (2014) In vitro salt stress induced enhancement of ascorbic acid in Emblica officinalis. Ann Plant Sci 3:588-593

Rai N, Tiwari L, Sharma RK, Verma AK (2012) Pharmaco-botanical profile on Emblica officinalis Gaertn. - a pharmacopoeial herbal drug. STM J 1:29-41

Rajak S, Banerjee SK, Sood S, Dinda AK, Gupta YK, Gupta SK, Maulik SK (2004) Emblica officinalis causes myocardial adaptation and protects against oxidative stress in ischemic-reperfusion injury in rats. Phytother Res 18:54-60

Reddy SM, Laxminarayana R (1984) Post infection changes in ascorbic acid contents of mango and aonla caused by two fruit rot fungi. Curr Sci 53:927-928

Reddy VD, Padmavathi P, Kavitha G, Gopi S, Varadacharyulu N (2011) Emblica officinalis ameliorates alcohol-induced brain mitochondrial dysfunction in rats. J Med Food 14:62-68

Renuka R, Devi KR, Sivakami M, Thilagavathi T, Uthrakumar R, Kaviyarasu K (2020) Biosynthesis of silver nanoparticles using Phyllanthus emblica fruit extract for antimicrobial application. Biocatal Agric Biotechnol 24:101567

Rose K, Wan C, Thomas A, Seeram NP, Ma H (2018) Phenolic compounds isolated and identified from amla (Phyllanthus emblica) juice powder and their antioxidant and neuroprotective activities. Nat Prod Commun 13:1934578X1801301019

Saeed S, Tariq P (2007) Antibacterial activities of Emblica officinalis and Coriandrum sativum against gram negative urinary pathogens. Pak J Pharm Sci 20:32-35

Sai RM, Neetu D, Yogesh B, Anju B, Dipti P, Pauline T, Sharma SK, Sarada SK, Ilavazhagan G, Kumar D, Selvamurthy W (2002) Cyto-protective and immunomodulating properties of Amla (Emblica officinalis) on lymphocytes: an in-vitro study. J Ethnopharmacol 81:5-10
Sampath Kumar KP, Bhowmik D, Dutta A, Pd Yadav A, Paswan S, Srivastava S, Deb L (2012) Recent trends in potential traditional Indian herbs Emblica officinalis and its medicinal importance. J Pharmacogn Phytochem 1:18-28

Sarkar R, Hazra B, Mandal N (2015) Amelioration of iron overloadinduced liver toxicity by a potent antioxidant and iron chelator, Emblica officinalis Gaertn. Toxicol Ind Health 31:656-669

Schenk RU, Hildebrandt AC (1972) Medium and techniques for induction and growth of monocotyledonous and dicotyledonous plant cell cultures. Can J Bot 50:199-204

Sehgal CB, Khurana S (1985) Morphogenesis and plant regeneration from cultured endosperm of Emblica officinalis Gaertn. Plant Cell Rep 4:263-266

Sengupta P, Sen S, Mukherjee K, Acharya K (2020) Postharvest diseases of Indian gooseberry and their management: a review. Int J Fruit Sci 20:178-190

Shalini B, Sharma J (2015) Beneficial effects of Emblica officinalis on fluoride-induced toxicity on brain biochemical indexes and learning-memory in rats. Toxicol Int 22:35-39

Sharma RR (2006) Fruit production: problems and solutions. International Book Distributing Company, Lucknow

Sharma A, Sharma KK (2011) Chemoprotective role of triphala against 1,2-dimethylhydrazine dihydrochloride induced carcinogenic damage to mouse liver. Indian J Clin Biochem 26:290-295

Sharma P, Joshi T, Joshi T, Chandra S, Tamta S (2020) In silico screening of potential antidiabetic phytochemicals from Phyllanthus emblica against therapeutic targets of type 2 diabetes. J Ethnopharmacol 248:112268

Singh A, Singh HK (2015a) Application of plant growth regulators to improve fruit yield and quality in Indian gooseberry (Emblica officinalis Gaertn.). J AgriSearch 2:20-23

Singh SK, Singh PK (2015b) Intercropping elephant foot yam is an economical cultivation practice for Indian goose berry (Phylanthus emblica) orchard management. New Agricult 26:357-363

Singh JK, Prasad J, Singh HK, Anshuman S (2008) Effect of micronutrients and plant growth regulators on plant growth and fruit drop in aonla (Emblica officinalis Gaertn.) fruits cv'.Narendra Aonla-10'. Plant Arch 8:911-913

Singh E, Sharma S, Pareek A, Dwivedi J, Yadav S, Sharma S (2011) Phytochemistry, traditional uses and cancer chemopreventive activity of amla (Phyllanthus emblica): the sustainer. J App Pharm Sci 2:176-183

Singh SK, Meghwal PR, Pathak R (2014) Molecular characterization of commercial varieties of Phyllanthus emblica Using RAPD and nuclear rDNA SNPs. Proc Natl Acad Sci India Sect B Biol Sci 85:971-978

Singh M, Sharma N, Paras HS, Hans NS, Singh NP, Sarin A (2019a) Antioxidative potential of Phyllanthus emblica for oxidation stability of biodiesels. Environ Prog Sustain Energy 38:721-726

Singh SN, Moses A, David A (2019b) Antimicrobial activity of Emblica officinalis extracts against selected bacterial pathogens. Int J Basic Appl Res 9:325-330

Singhal RV, Rajwar GS, Bhutiani R (2017) Effect of different growth nutrients and soil composition on the growth of Emblica officinalis Gaertn, a medicinal plant. Int J Eng Sci Res 7:143-154

Srikumar R, Parthasarathy NJ, Sheela DR (2005) Immunomodulatory activity of triphala on neutrophil functions. Biol Pharm Bull 28:1398-1403

Srikumar R, Parthasarathy NJ, Shankar EM, Manikandan S, Vijayakumar R, Thangaraj R, Vijayananth K, Sheela DR, Rao UA (2007) Evaluation of the growth inhibitory activities of triphala against common bacterial isolates from HIV infected patients. Phytother Res 21:476-480

Srinivasan P, Vijayakumar S, Kothandaraman S, Palani M (2018) Anti-diabetic activity of quercetin extracted from Phyllanthus 
emblica L. fruit: In silico and in vivo approaches. J Pharm Anal 8:109-118

Sriwatcharakul S (2020) Evaluation of bioactivities of Phyllanthus emblica seed. Energy Rep 6:442-447

Sultana S, Ahmad S, Khanand N, Jahangir T (2005) Effect of Emblica officinalis (Gaertn) on $\mathrm{CCl}$ induced hepatic toxicity and DNA synthesis in Wistar rats. Indian J Exp Biol 43:430-436

Sumbali G, Badyal K (1990) New records of fungal species associated with fruit rot of Phyllanthus emblica Linn. Indian J Mycol Plant Pathol 20:202-203

Sumitra M, Manikandan P, Gayathri VS, Mahendran P, Suguna L (2009) Emblica officinalis exerts wound healing action through up- regulation of collagen and extracellular signal-regulated kinases (ERK1/2). Wound Repair Regen 17:99-107

Suresh PM, Kumar S (2014) Impact of drip fertigation levels on flower characters in aonla (Emblica officinalis Gaertn.) cv. NA-7. Trends Biosci 7:1723-1725

Suresh PM, Kumar S, Swaminathan V, Gurusamy A, Shivakumar T (2019) Influence of drip fertigation on soil NPK status of aonla ((Emblica officinalis) Gaertn.) cv. NA-7. Chem Sci Rev Lett 8:29-34

Thilaga S, Largia MJV, Parameswari A, Nair RR, Ganesh D (2013) High frequency somatic embryogenesis from leaf tissue of 'Emblica officinalis' Gaertn. - a high valued tree for non-timber forest products. Aus J Crop Sci 7:1480

Thilaga S, Nair RR, Kannan MR, Ganesh D (2017) RAPD markers for screening shoot gall maker (Betousa stylophora Swinhoe) tolerant genotypes of amla (Phyllanthus emblica L.). J Genet Engg Biotechnol 15:223-330

Treadway L (1994) Amla traditional food and medicine. Herbal Gram $31: 26$

Upadya H, Prabhu S, Prasad A, Subramanian D, Gupta S, Goel A (2019) A randomized, double blind, placebo controlled, multicenter clinical trial to assess the efficacy and safety of Emblica officinalis extract in patients with dyslipidemia. BMC Complement Altern Med 19:27

Variya BC, Bakrania AK, Patel SS (2016) Emblica officinalis (Amla): A review for its phytochemistry, ethnomedicinal uses and medicinal potentials with respect to molecular mechanisms. Pharmacol Res 111:180-200

Vasant RA, Narasimhacharya AV (2012) Amla as an antihyperglycemic and hepato-renal protective agent in fluoride induced toxicity. J Pharm Bioallied Sci 4:250-254

Vashisht BB, Singh CB, Biwalkar N (2018) Establishment and growth of Aonla (Emblica officinalis) as affected by irrigation and mulching in the Shivaliks of Punjab. J Soil Water Conserv 17:98-101

Vasudevan M, Parle M (2007) Effect of Anwala churna (Emblica officinalis Gaertn.): an ayurvedic preparation on memory deficit rats. Yakugaku Zasshi 127:1701-1707

Veena KP, Shanthi SP (2006) The biochemical alterations following administration of Kalpa amrutha and Semecarpus anacardium in mammary carcinoma. Chem Biol Interact 161:69-78

Verma B, Kant U (1999) Propagation of Emblica officinalis Gaertn. through tissue culture. Adv Plant Sci 12:21-25

Verma RS, Singh PC, Chaturvedi OP (2008) Effect of foliar sprays of zinc and boron on the physical parameters of aonla (Emblica officinalis Gaertn.) fruits cv. Banarasi. Asian J Hort 3:344-345

Verma SK, Das AK, Patel MK, Shah A, Kumar V, Gantait S (2018) Engineered nanomaterials for plant growth and development: A prospective analysis. Sci Total Environ 630:1413-1435

Verma SK, Das AK, Gantait S, Kumar V, Gurel E (2019) Applications of carbon nanomaterials in the plant system: a perspective view on the pros and cons. Sci Total Environ 667:485-499

Wali VK, Bakshi P, Jasrotia A, Bhushan B, Bakshi M (2015) Aonla. SKUAST-Jammu, India, p 30

Warude D, Chavan P, Joshi K, Patwardhan B (2003) DNA isolation from fresh and dry plant samples with highly acidic tissue extracts. Plant Mol Biol Rep 21:467a-467f

White PR (1963) The cultivation of animal and plant cells. 2nd Ed, Ronald Press Co., New York. ISBN: 0826093809, pp 22

Wiart C (2013) Note on the relevance of Emblica officinalis Gaertn. for the treatment and prevention of cancer. Eur J Cancer Prev 22:198

Xie T, Wang W-P, Mao Z-F, Qu Z-Z, Luan S-Q, Jia L-J, Kan M-C (2012) Effects of epigallocatechin-3-gallate on pentylenetetrazole-induced kindling, cognitive impairment and oxidative stress in rats. Neurosci Lett 516:237-241

Yadav VK, Singh HK (1999) Studies on the preharvest application of chemicals on shelf life of aonla (Emblica officinalis Gaertn.) fruits at ambient temperature. J Appl Hort 1:118-121

Yadav S, Shukha HS, Ram RA (2010) Studies on foliar of NAA, GA boric acid and $\mathrm{Ca}\left(\mathrm{NO}_{3}\right)_{2}$ on fruit retention, growth, application yield and quality of aonla (Emblica officinalis Gaertn.) cv. Banarasi. Hort J 23:64-67

Yadav SS, Singh MK, Singh PK, Kumar V (2017) Traditional knowledge to clinical trials: a review on therapeutic actions of Emblica officinalis. Biomed Pharmacother 93:1292-1302 